\title{
In vitro and in vivo anti-Trypanosoma cruzi activity of
}

new arylamine Mannich base-type derivatives.

Elsa Moreno-Viguri, ${ }^{\dagger, \ddagger}$ Carmen Jiménez-Montes ${ }^{\S, \ddagger}$ Rubén Martín-Escolano, $^{\S}$ Mery Santivañez-Veliz, ${ }^{\dagger}$ Alvaro Martin-Montes, ${ }^{\S}$ Amaya Azqueta, ${ }^{\neq}{ }^{\ddagger}$ Marina Jimenez-Lopez, ${ }^{\S}$ Salvador Zamora Ledesma, ${ }^{\S}$ Nuria Cirauqui, ${ }^{\ddagger}$ Adela López de Ceráin, ${ }^{\sharp, \dagger}$ Clotilde Marín, ${ }^{\S}$ Manuel Sánchez-Moreno, ${ }^{\S, *}$ Silvia Pérez-Silanes ${ }^{\dagger, *}$

${ }^{\dagger}$ Department of Organic and Pharmaceutical Chemistry, Institute of Tropical Health, Universidad de Navarra, Pamplona, Spain. ${ }^{\sharp}$ Department of Pharmacology and Toxicology, Universidad de Navarra, Pamplona, Spain. IdiSNA, Navarra Institute for Health Research, Recinto de Complejo Hospitalario de Navarra, Pamplona, Spain. ${ }^{\S}$ Departamento de Parasitología, Instituto de Investigación Biosanitaria (ibs.GRANADA), Hospitales Universitarios De Granada/Universidad de Granada, Granada, Spain. ${ }^{\ddagger}$ Department of Pharmaceutical Sciences, Federal University of Rio de Janeiro, Rio de Janeiro, Brazil.

ABSTRACT. Chagas disease is a neglected tropical disease with 6-7 million people infected worldwide and there is no effective treatment. Therefore, there is an urgent need to continue researching in order to discover novel therapeutic alternatives. We present a series of arylaminoketone derivatives as means of identifying new drugs to treat Chagas disease in the acute phase with greater activity, less toxicity and with a larger spectrum of action than that corresponding to the reference drug benznidazole. Indexes of high selectivity found in vitro formed the basis for later in vivo assays in BALB/c mice. Murine model results show that compounds 3, 4, 7 and $\mathbf{1 0}$ induced a remarkable decrease in parasitemia levels in acute phase and the parasitemia reactivation following immunosuppression, and curative rates were higher 
than with benznidazole. These high anti-parasitic activities encourage us to propose these compounds as promising molecules for developing an easy to synthesize anti-Chagas agent.

\section{INTRODUCTION}

Chagas disease (CD), is caused by the protozoa Trypanosoma cruzi (T. cruzi) which is naturally transmitted by hematophagous insects, presents risk factors strongly linked to low socioeconomic factors and it is classified as a neglected tropical disease according to WHO. ${ }^{1,2} \mathrm{CD}$ is one of the most important medical problems in rural areas of the 21 endemic Latin America countries. Moreover, in the past decades migration and travelling have extended the spread of $C D$ to other continents including North America, ${ }^{3}$ Europe $^{4}$ and parts of the Western Pacific, ${ }^{5}$ where there is now a significant number of individuals with this disease. The worldwide incidence of $\mathrm{CD}$ has decreased thanks to the control programs; however, an estimated 6-7 million persons are infected worldwide. ${ }^{6}$ Approximately $20 \%$ of Latin American countries are endemic for this disease and up to $30-40 \%$ of patients will suffer chronic form of the disease in their lifetimes-i.e. important cardiac or digestive problems.

Currently, the two drugs recommended for CD are benznidazole (BZN) and nifurtimox (NFX) ${ }^{7,8}$ In general terms, BZN is the first line drug in most endemic countries ${ }^{9}$ because it is tolerated better but some of its secondary effects include dermatitis or neuropathy. Both drugs reduce parasitism during the acute and early CD stage, but drug efficacy during the chronic phase is limited. In addition, the efficacy of BNZ and NFX could change according to the geographical area, as consequence of a different susceptibility of the drugs by the different strains of $T$. cruzi. ${ }^{10}$ This background, including side effects and therapeutic deficiencies of these drugs, justifies the urgent need to continue researching in order to discover novel therapeutic alternatives. The ideal drug defined by its Target Product Profile (TPP) is outlined in Table 1. Briefly, it should present an efficacy at least equal to BZN and with a better safety profile. An oral drug in once-a-day in-house treatment for less than 30 days is desired and the new drug should be active against most parasite species. ${ }^{11-13}$ 
Table 1. Proposed TPP for Chagas disease modified from DNDi. ${ }^{11}$

Drug repositioning has emerged as one of the most fruitful strategies for improving and accelerating the drug development process. This strategy has become one of the most powerful tools for identifying compounds for the treatment of a disease different from the one they were originally designed for, used not only in the academic field but also in pharmaceutical companies. Different methods are considered under this strategy but 28 out of the 50 small molecules approved by the FDA between 1999 and 2008 were discovered by phenotypic based drug design. ${ }^{14,15}$ In this context we decided to screen our in-house chemical laboratory library with the purpose of searching drugs against of CD. ${ }^{16-21}$ We found some arylamine Mannich base derivatives tested before for their in vitro affinity at the 5-HT transporter and $5 \mathrm{HT}_{1 \mathrm{~A}}$ receptors ${ }^{17}$ or $5-\mathrm{HT}_{7}^{20}$ receptors as potential antidepressants and against Plasmodium falciparum as a potential antimalarials ${ }^{19}$ and in every case they were not active. However risk of potential off-target activities derived from a possible CSN activity is unlikely.

Herein we present the synthesis of arylaminoketone-type compounds and their in vitro evaluation against $T$. cruzi. Furthermore we show that the preliminary genotoxicity screening test revealed that this family of compounds is not genotoxic with or without metabolic activation, thereby providing the ideal chemical space for the development of new, potent and safe agents for the treatment of CD. Highselectivity indexes and the genotoxicity screening have been the established cut-off to move into in vivo assays in BALB/c mice, where fresh blood examination was used to quantify the parasitemia. Also a cure was assayed by PCR, as was the reactivating of parasitemia in blood following immunosuppression. The mechanism of action has been explored at metabolic levels by ${ }^{1} \mathrm{H}$ Magnetic Nuclear Resonance, and the study has been completed by testing their activity as potential FeSuperoxide dismutase inhibitors. Using computational approaches, we suggest a binding mode for the compounds to the enzyme.

\section{RESULTS AND DISCUSSION}


Chemistry. It is essential to identify the purpose of the synthesis of new small molecules. During the drug discovery process, mainly when facing NTD, the synthetic routes should allow the preparation of an important amount of different small molecules with a variety of substituents in order to explore and modify polarity, solubility, volume, rigidity and some other parameters that could influence activity and toxicity. Cost and commercial availability of chemicals should also be taken into consideration as well as the solvent and waste volumes. With these ideas in mind, the retrosynthetic analysis of the target compounds (1-20) suggested methylketones and arylamines as the appropriate building blocks (Table 2). Compounds could be prepared in one step synthetic route with exception of compounds 10 and 13. In this case, both arylamines had to be prepared as previously reported. ${ }^{17,20}$ The general method shown in Figure 1 was used to prepare the compounds presented in this work. The desired compounds were obtained condensing the adequate methylketone (commercially available) with the appropriate arylamine via Mannich reaction in acidic medium and using 1,3-dioxolane as the solvent and source of formaldehyde.

Table 2. Relationship of synthesized compounds.

Figure 1. General method of synthesis of new arylaminoketone derivatives.

The results of the in silico study of some relevant molecular properties related to the drug-likeness of the compounds are shown in Table 3. It can be observed that none of them have a molecular weight higher than $500 \mathrm{~g} / \mathrm{mol}$, or an estimated partition coefficient $(\log P)$ higher than 5 . Compounds 3, 6, 10, 15 and 19 present a number of hydrogen-bond acceptors higher than 5 but lower than 10, while the number of donors is lower than 5 for all compounds. Therefore, all compounds fulfill the Lipinski "rule of five”. Finally, together with the acceptable partition coefficient values, the Polar Surface Area (PSA) of the compounds is lower than $140 \AA^{2}$, and the aqueous solubility $(\log S)$ is similar or higher than -4 , which anticipates good oral bioavailability.

Table 3. Molecular properties of the new compounds calculated with the DataWarrior program. $^{22}$ 
In vitro Trypanocidal Evaluation. Information was gathered by the in vitro evaluation of activity of compounds 1-20 with respect to intra- and extracellular forms of T. cruzi SN3, Arequipa and Tulahuen strains obtained as detailed in the experimental section. Assays have been carried out in strains from different locations, hosts and tropisms, in order to determine if there are any differences in drug performance.

Extracellular form (epimastigote) is the most commonly used owing to its easy culture in laboratory, but tests obtained on intracellular amastigotes (responsible for the chronic phase of CD) and blood trypomastigotes are more indicative due to these form of the parasite is the developed form in vertebrate hosts $^{23}$. According to some authors, for deeming a compound as potential antichagasic agent, it has to meet certain criteria ${ }^{24}$. In the first place, the $\mathrm{IC}_{50}$ value has to be around $10 \mu \mathrm{M}$ and the in second place the SI has to be 50 times higher than that of the reference drug. $\mathrm{IC}_{50}$ values for the 3 studied strains in both their extracellular and intracellular forms are shown in Table 4.

Table 4 shows the $\mathrm{IC}_{50}$ values found at $72 \mathrm{~h}$ exposure using concentrations of $1-100 \mu \mathrm{M}$ on assaying compounds $1-20$ vs. 3 strains studied and the 3 forms of parasite cited above. The $\mathrm{IC}_{50}$ values for the drug BZN (reference) served for comparisons. Ten compounds (3, 4, 7, 10, 11, 13-15, 18 and 19) were shown to fulfill this first requisite. It was shown that the compounds meet this first requirement. Those compounds are the most active of the tested compounds for the three parasite forms assayed with an $\mathrm{IC}_{50}$ value lower than the one corresponding to the reference drug.

Table 4. In vitro activity and toxicity for the 20 arylaminoketone derivatives on extra- and intracellular forms of Trypanosoma cruzi strains.

On the other hand, the cytotoxicity of compounds 1-20 was tested against Vero cells (Table 5) and a lesser cytotoxicity than the one of the reference drug was observed. Interestingly, toxicity data against Vero cells after 72 h of culture showed that all derivatives assayed were considerably less cytotoxic than drug reference BZN. Cytotoxicity $\mathrm{IC}_{50}$ values ranged from $30.1 \mu \mathrm{M}$ to $2846.3 \mu \mathrm{M}$ in sharp contrast with that obtained for BZN (13.6 $\mu \mathrm{M})$. Only compounds 11 and $\mathbf{1 8}$ were more cytotoxic than BZN. 
Table 5. Selectivity index and in vitro toxicity for the 20 derivatives of arylaminoketone intra and extracellular of $T$.cruzi strains.

In accordance with the above in vitro data, Table 5 presents the most notable selectivity index (SI) values, indicating in brackets how often the SI of each compound surpassed the SI of BNZ. This Table 5 shows that excellent results were found for compounds 3, 4, 7 and 10 in all the parasite forms tested. Those drugs were chosen for further in vitro and in vivo assays and the possible mechanisms of action. In this case experiments were carried out only in the Arequipa strain as there are no significant differences between the performances of the compounds on the other studied strains.

From a structural point of view, it can be said that the benzothiophene derivatives are less cytotoxic than the rest of the derivatives. All of the benzothiophene derivatives (1-10) present $\mathrm{IC}_{50}$ in Vero cells higher than $70 \mu \mathrm{M}$; moreover, the selected compounds $(\mathbf{3 , 4 , 7 , 1 0})$ present $\mathrm{IC}_{50}$ higher than $700 \mu \mathrm{M}$ in contrast with BZN $(13.6 \mu \mathrm{M})$.

In vitro genotoxicity screening test. The potential genotoxicity of the compounds $(1-5,7,10,14,16-$ 18) was screened using the SOS/umu test. The concentrations tested for each compounds were previously determined in a toxicity study in the test system. The SOS/umu screening test revealed that none of the tested compounds were genotoxic with or without metabolic activation. Meanwhile, both NFX and BZN were also tested and both of them were genotoxic in the tested conditions. The main purpose of including the SOS/umu test in the preliminary assays is to study the genotoxicity capacity of the most active compounds in vitro so that only compounds that are not genotoxic will move on to further studies. This test is convenient as a screening assay because it is a fast, simple and efficient method for testing the genotoxicity of a large number of samples. For these reasons, compounds $\mathbf{3}, \mathbf{4}$ and $\mathbf{7}$, that had met the criteria for being moved on to in vivo models, were included in the SOS/umu test. Moreover, compounds 1, 2, 5, 10, 14 and 16-18 had been previously assayed in the genotoxicity screening test. These compounds came from our in-house chemical library and their in vitro trypanocidal activity had been studied, showing interesting results. Therefore and before synthesizing 
new related derivatives, we decided to explore their genotoxicity capacity to be sure that these new derivatives could be promising not only because of their potency but also because of their safeness.

Both the trypanocidal activity and genotoxicity screening test mentioned above supported the idea of carrying out more detailed in vitro and in vivo assays with benzothiophenes 3, 4, 7 and 10 in order to get more information about their mode of action and their apparent advantages with respect to drug reference BZN.

Infectivity assay. For fuller knowledge concerning the trypanocidal action of four compounds (3, 4, 7 and 10), a subsequent determination was made of their impact on the intracellular replication and infectivity of amastigotes of T. cruzi (Figure 2). A sharp decline in the infection rate of the host cell occurred when the benzothiophene derivatives 3, 4, 7 and 10 were added to the infected Vero cells. Also, the four compounds proved to have greater effectiveness than did the reference drug, this reducing the infective capacity by $22 \%$ on day 10 . (Figure 2A). Measuring of the mean number of amastigotes per infected Vero cell (Figure 2B) led to similar results: at the end of the treatment, the benzothiophene derivatives had decreased the number of amastigotes present in the cells by 45 to $74 \%$, whereas BZN allowed only a poor reduction of 30\%. With regard to the number of trypomastigote forms released in the medium (Figure 2C), on the whole, inhibition values were less significant. Even so, all the compounds showed a reduction by 47 to $68 \%$ and almost doubled the inhibitory effect of BZN (20\%), which clearly remained less effective. Ultimately, infectivity tests confirmed the in vitro antiparasitic activity shown in Table $\mathbf{4}$ and $\mathbf{5}$ for the four compounds, and also their higher efficacy with respect to the reference drug.

Figure 2. Reduction of the infection of Trypanosoma cruzi in Vero cells treated with (-m-) BZN, (- $\Delta-)$

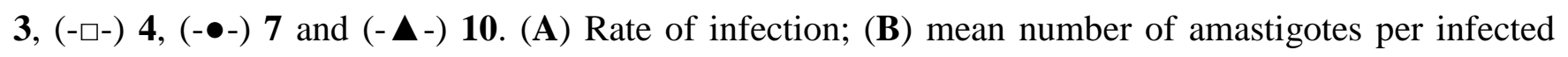
Vero cells; $(\mathbf{C})$ number of trypomastigotes in the culture medium. Measured at $\mathrm{IC}_{25} \cdot$ Values are the means of the three separate experiments. 
In Vivo Anti-T. cruzi Activity in BALB/c Albino Female Mice. Since compounds 3, 4, 7 and 10 exhibited notable in vitro SI values in comparison to BZN (the reference drug) and the screening test showed no genotoxicity, those compounds were employed in more in vivo studies using BALB/c mice. Their ant-trypanosomal action prior to the acute CD phase to 40 days post-infection (pi) was studied first. Infection was imposed by intraperitoneal inoculation of metacyclic blood trypomastigotes $\left(5 \times 10^{5}\right)$ using Arequipa T. cruzi which results in lower mortality than do other approaches ${ }^{25}$, and compound doses of 50 and $100 \mathrm{mg} / \mathrm{kg}$ body weight were tested by oral administration on alternating days (7-15 days pi). The parasites were counted in $5 \mu \mathrm{L}$ blood samples taken from the mandibular vein. Notably, no mice died after receiving compounds 3, 4, 7 and 10. Figure 3 shows the effect caused by the benzothiophene derivatives on the parasitemia levels in blood during the acute phase of CD (day 0-40 pi). (In Figure 3 only the results for the experiments performed with $100 \mathrm{mg} / \mathrm{kg}$ body weight dose are shown; not showing results for experiments with $50 \mathrm{mg} / \mathrm{kg}$ body weight dose, due to the evident majority effect of this first dose). A reduction of parasitemia in mice treated with the tested compounds was evident as soon as the very beginning of the treatment (day 7 pi), and it was maintained until the end of the acute phase (day 40 pi), and not only until the end of period of treatment (day 15 pi). In Figure 3 shows that mice treated with compounds 4 and 7, parasitemia was undetected in day 25 pi. This appears to indicate that parasites were eliminated, or their number depleted to non-detectable levels with a 100 dilution factor for counting in optic microscope, or maybe they migrated to organs. In the three detailed cases, they could no longer be detected in blood.

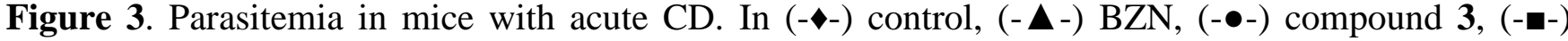
compound 4, (- $\left.\Delta_{-}\right)$compound 7 and (-口-) compound 10. In all cases, compounds were orally administered using, for each compound, $100 \mathrm{mg} / \mathrm{kg}$ of body mass. Values constitute means of six mice \pm standard deviation. Treatment days are represented in grey.

Performance of drugs during the chronic phase (where currently used drugs are not as effective as they should) was tested. ${ }^{26,27}$ The parasitemia remaining in blood at day 90 pi is practically undetectable 
due to the parasite, in the amastigote form, is nested inside target organs. This involves that immunocompromised individuals cured with apparent success show high reactivation ability of the parasitemia. Furthermore, apparently cured patients submitted to liver or kidney transplantation, treated with anticancer chemotherapy or diagnosed with AIDS, showed clinically highly aggressive CD reactivation. As a means of providing information on this question, mice that were treated as indicated above, at 90 days pi received three successive immunosuppression cycles using cyclophosphamide monohydrate, as described above. ${ }^{28}$ The aim was to reactivate the parasitemia, previously under the control of the immunological system of the mice. The tridimensional graph of Figure 4 shows the reactivation caused by compounds due to this reactivation is proportional to the survival rate of the parasites. Parasitemia reactivation reached $65 \%$ with respect to the acute phase in the control group of infected and untreated mice, whereas it decreased to $0 \%$ in the treated mice with $100 \mathrm{mg} / \mathrm{kg}$ body weight group revealing a significant effect on the chronic course of infection. Moreover, it can be observed that parasitemia reactivation decreased to $0 \%$ in mice treated with compound 7 not only with $100 \mathrm{mg} / \mathrm{kg}$ but also with $50 \mathrm{mg} / \mathrm{kg}$.

Figure 4. Immunosuppression in vivo assay for mice untreated and treated with $100 \mathrm{mg} / \mathrm{kg}$ of body mass of BZN, 3, 4, 7 and 10. Figure shows the reactivation of blood parasitemia after the immunosuppression cycles by fresh blood containing parasitemia to the peak day during acute phase.

ELISA (enzyme-linked immunosorbent assay) was employed to detect the total Ig-G levels using FeSOD isolated by us as antigen source. An assessment of the immune status of the mice was made possible by the detection of total IgG, since this reflects the protection level that should be ascribed to the compounds tested, in combination with the animal's natural protection. Results from the experiments using ELISA were verified using the parasitemia assay conducted as described above (Figure 5). The ELISA test indicated that the mice receiving compounds 3, 4, 7, and 10 maintained steady total IgG levels, as chronically infected mice also did; levels proved lower than in control after immunosuppression, whereas control levels rose following parasitemia reactivation.

Figure 5. Shows differences in the IgG levels measured by ELISA at different day post-infection. 
Finally the curative effect of the compounds in the extracted target organs was evaluated. Figure 6 only shows the PCR results of organs in the different groups of mice treated with $100 \mathrm{mg} / \mathrm{kg}$ body weight, because this dosage had better results. The controls showed the ubiquitous presence of the parasite in the 8 target organs. In addition, the figure shows the group of mice treated with BZN, in which 6 out of 8 target organs were infected. In contrast, the group of mice treated with the compounds 3, 4, 7 and 10 showed less infected target organs than reference drug BZN, especially compounds 4 and 7. Every organ of mice treated with drug 4 was not infected. In the case of compound 7, target organs were also not infected, while the two remaining target organs presented 83\% less parasites than control. Cure assessment in chronic T. cruzi infection is controversial, mainly because of the lack of reliable tests to ensure parasite elimination. ${ }^{29}$ We should mention that identifying by PCR whether experimental animals have been cured is a critical question. This technique is able to detect a single parasite in $5 \mathrm{ml}$ of blood and the main utility is to confirm failure to cure, because even consistently negative results cannot prove that tissue parasites have been completely eliminated. ${ }^{30,}{ }^{31}$ Bioluminiscence imaging models techniques are being used currently to determinate if experimental animals have been cured. However, we can state that there are many evidences of cure (or, at least, a considerable reduction of the number of parasites), so the negative results of 5 independent samples by PCR and the absence of reactivation in blood after immunosuppression (double checking for demonstrating cure). Immunosupresion is the formula to demonstrate curation in all animal testing models, either bioluminescence-based tests or the ones that employ PCR as double checking ones. ${ }^{32}$

The detection methodology has been improved significantly by specific PCR of genes and sequences with the development of the technology TaqMan, in the use of fluorogenic probes and the measurement of real-time amplification reaction used in the detection of sequences of constant regions and variables of minicircles of kinetoplast DNA. These results are quite useful to measure the parasitic load in chronic patients earlier and later after the treatment, and for the future establishment of reliable criteria of patient healing submitted to therapy.$^{33}$ 
Figure 6. Polymerase chain reaction (PCR) analysis of the 8 target organs on day 120 after infection. Lanes: M, base pair marker; 1: PCR negative control; 2: PCR positive control; 3: PCR adipose tissue; 4: PCR brain tissue; 5: PCR heart tissue; 6: PCR esophagus tissue; 7: PCR stomach tissue; 8: PCR bone marrow tissue; 9: PCR muscle tissue; 10: PCR lung tissue. * This means that 1/6 of the corresponding organ PCR products showed 300 bp band on electrophoresis.

Finally, Table 6 shows weight percentage of spleens from different groups of mice in both doses of 50 and $100 \mathrm{mg} / \mathrm{kg}$ body weight. Control group showed more weight percentage when compared with both groups of mice treated with 50 and $100 \mathrm{mg} / \mathrm{kg}$ body weight, which means that all compounds reduced splenomegaly and, therefore, infection rates. Moreover, groups of mice treated with $100 \mathrm{mg} / \mathrm{kg}$ body weight showed less weight percentage compared with the same groups of mice treated with a dosage of $50 \mathrm{mg} / \mathrm{kg}$ body weight. Compounds 3 and 7 showed lower splenomegaly.

Table 6. Weight percent of spleens of different groups of mice.

Inhibition of the T. cruzi Fe-SOD Enzyme. The most studied therapeutic targets are enzymes, one of them is the trypanosomatid Fe-SOD, which presents structural and biochemical differences with respect to their human homologues. This enzyme plays a crucial role allowing the cell to avoid damage caused by the oxidative burst. ${ }^{34,35}$ Taking this in account, we have given importance to iron superoxide dismutase (Fe-SOD), a trypanosomatid exclusive enzyme that is absent in other eukaryotic cells. ${ }^{36,37}$ Alternatively, trypanosomatids have a shared redox system in which trypanothione and glutathione team up to protect the parasite from reactive oxygen species (ROS). Trypanothione [bis(glutathionyl) spermidine] is synthesized from spermidine, the major polyamine in these parasites. Therefore, alterations in the biosynthesis of this amine can interfere in the defense mechanisms of the parasites against oxidative stress. Also noteworthy is the trypanothione synthase enzymes (trys) and trypanothione reductase (tryr), involved in the biosynthetic process trypanothione, which is the main defense system against oxidative trypanosomatids damage. The enzyme glutathione peroxidase constitutes the third block of main antioxidant enzymes of the parasite. ${ }^{38,39}$ 
As mentioned above, the antiparasitic activity of other benzothiophene derivatives partly accounted for by their inhibition of parasitic SOD. This could view as a possible target for designing new molecules capable of acting on metal ion carried within their structure. ${ }^{40-42}$

As a means of gaining more evidence in this regard, the effects exerted on T. cruzi Arequipa strain FeSOD by compounds $3, \mathbf{4 , 7}$ and 10 were assessed at concentrations of between $1 \mu \mathrm{M}$ to $100 \mu \mathrm{M}^{43}$ Figure 7A shows the data on inhibition, and the related $\mathrm{IC}_{50}$ values appear in brackets. Figure $\mathbf{7 B}$, for comparative purposes, presents the action of these same compounds regarding CuZn-SOD from human erythrocytes. Reflecting that the four compounds acted against Fe-SOD. Nevertheless Figure 7A indicates that the most trypanocidal compounds 3, $\mathbf{7}$ and $\mathbf{1 0}$ highly inhibited the enzyme activity, while the inhibitory activity of compound $\mathbf{4}$ was clearly lower. The graph shows that benzothiophene $\mathbf{3}$ reached $100 \%$ inhibition of Fe-SOD at a $50 \mu \mathrm{M}$ concentration and with an $\mathrm{IC}_{50}$ of $7.8 \mu \mathrm{M}$ and that compounds $\mathbf{7}$ and $\mathbf{1 0}$ almost reached 100\% inhibition at a slightly lower concentration, with IC $_{50}$ values of 16.8 and $71.1 \mu \mathrm{M}$ respectively. As the assay against FeSOD shows, compound 4 is the least efficient, as shown in its in vivo effects. However, it had curative effect in chronic phase. Some other mechanisms of action could be considered and the chance of a multi target compound should not be discarded.

Figure 7. A) Inhibition in vitro (\%) of Fe-SOD from epimastigotes of Trypanosoma cruzi for compounds (activity $25.4 \pm 3.1 \mathrm{U} / \mathrm{mg}$ ). B) Inhibition in vitro (\%) of CuZn-SOD from human erythrocytes for compounds (activity $23.36 \pm 2.5 \mathrm{U} / \mathrm{mg}$ ). Activity differences in the control homogenate vs. the sample incubated using compounds were identified by the Newman-Keuls test. Values are the average of three separate rate determinations.

Interestingly, the effect of compound 3 on human CuZn-SOD was substantially similar to the case of Fe-SOD (Figure 7A), since inhibitory activity scarcely reached $100 \%$ at the $50 \mu \mathrm{M}$ concentration. The other three compounds (4, 7 and 10) did not show inhibition to CuZn-SOD, not even at $100 \mu \mathrm{M}$. These compounds are remarkable selective inhibitors of Fe-SOD. 
Metabolite excretion. Trypanosomatids proved incapable of completely degrade glucose to $\mathrm{CO}_{2}$, thus excreting into the medium part of their hexose skeleton as partly oxidized fragments. The percentage and nature of this excretion depended on the pathway that was used in glucose metabolism. ${ }^{44}$ In $T$. cruzi, the catabolism product are mainly acetate, succinate, L-alanine and D-lactate. ${ }^{45}$

In order to obtain some information about the effects of $3,4,7$ and 10 on the glucose metabolism of the parasite, we registered the ${ }^{1} \mathrm{H}$ NMR spectrum of $T$. cruzi epimastigotes treated with the test compounds (Supl information); the final excretion products were qualitatively and quantitatively identified. Figure 8 shows the results obtained and the comparison with control epimastigotes. Excretion of some metabolites, were disturbed in the treatment with the compounds, with the succinate being the most affected, and showing an increase of 199\% for compound 10, 142\% for compound 3, 22 $\%$ for 4 and an increase of 109\% for compound 7; lesser alterations were observed in the other metabolites.

All of these data could be interpreted on the basis of a change in the succinate pathways occurring in the presence of the compounds under investigation. Otherwise, it is interesting to note that the increase in succinate with these compounds indicates catabolic changes that could be related to mitochondria malfunction, due to the redox stress produced by inhibition of the mitochondrion-resident Fe-SOD enzyme. $^{46}$

Figure 8. Percentages of variation among peaks of catabolites excreted by epimastigotes of Trypanosoma cruzi exposed to compounds $3, \mathbf{4}, \mathbf{7}$ and $\mathbf{1 0}$ at their $\mathrm{IC}_{25}$ in comparison to a control incubated $96 \mathrm{~h}$.

\section{Mutagenicity studies. Ames test}

Taking into account the great potential of compounds $\mathbf{4}$ and $\mathbf{7}$, we decided to include them in the Ames test to explore their mutagenicity capacity before considering them for further preclinical development. The results obtained from the Ames test for compound $\mathbf{4}$ and $\mathbf{7}$ are shown in Tables $\mathbf{7}$ and 8, respectively. The evaluated doses of the compound were determined in a previous solubility study on 
the test system and $2.25 \mu \mathrm{g} /$ plate and $0.75 \mu \mathrm{g} /$ plate were established as the highest concentrations to be tested in the experimental conditions for compounds $\mathbf{4}$ and $\mathbf{7}$, respectively. No signs of cytotoxicity or precipitation were observed during the experiment. Both compounds were not mutagenic in any of the two tested conditions, as no evidence of dose-related or more than two-fold increase in the mean number or revertants was observed with or without metabolic activation. Therefore, compounds $\mathbf{4}$ and $\mathbf{7}$ could be pointed as interesting candidates for the development of an anti-Chagas agent

Table 7. Results of the Ames test of compound 4.

Table 8. Results of the Ames test of compound 7.

\section{Docking study of benzothiophenes 3, 4, 7 and 10 in the T. cruzi Fe-SOD and the human CuZn-} SOD enzymes.

In order to gain insight into the binding mode of the new benzothiophene derivatives in the Fe-SOD enzyme, docking studies were carried out using the crystal structure of both mitochondrial (PDB id 4DVH) and cytosolic (PDB id 2GPC) Fe-SOD trypanothione cruzi proteins. The results showed that the compounds bind in a deep funnel at the top of the dimer interface, which gives access to the active site (metal site) (Figure 9a). This cavity has already been suggested as the inhibitor binding site. ${ }^{47}$ Even when the binding mode of the compounds in both enzymes was similar, the affinity was higher for the mitochondrial protein. However, we believe that this is merely an artifact produced by the different orientation of Lys36 (Lys35 in the mitochondrial enzyme), which lays inside the active site in the PDB 2GPC and outside of it in PDB 4DVH. Based on our studies, we suggest the mitochondrial protein with PDB code 4DVH as best suited for docking studies on Fe-SOD trypanothione cruzi enzyme. The compounds bind in an aromatic pocket formed by aminoacids Try32, His28, Trp161 and Phe119. This hydrophobic pocket is flanked by polar residues at both sides: Glu162, Arg173, Val116 and Asn117 at one side, and Lys35 and Gln68 at the other. Just like the fluoro substituents of compounds 4 and $\mathbf{7}$, the nitro group of compounds $\mathbf{3}$ and $\mathbf{1 0}$ perform electrostatic interactions with Lys35, Gln68 and Asn117. As expected, the ligand does not perform interactions with the metal, which binds well inside the active 
site. However, it could act by inhibiting substrate access to the active site, or even by disrupting dimerization, as observed for other Fe-SOD inhibitors. ${ }^{48}$

Docking studies of the four compounds on the human CuZn-SOD were also carried out in order to understand the reason for compound 3 presenting no selectivity, contrary to the other three compounds. Previous crystal structures show that organic fragments bind to this enzyme in different regions of its surface. $^{49,50}$ Our blind docking results coincide with this observation, no single binding site was found. However, for all four compounds, one of the two best scored poses presented the inhibitor bound on the dimer interface. This interface has already been suggested as the inhibitors binding site. ${ }^{51,52}$ Therefore, we decided to perform another docking run defining this one as binding region. The results suggest a binding score around 10 times higher for compound $\mathbf{3}$ when compared with the other three compounds, coinciding with our experimental findings. Our docking results show compound 3 performing electrostatic interactions between the sulfur atom and Asp53, and between the nitro group and Lys9. Both interactions are absent in the other compounds (Figure 9b).

Figure 9. Docking results for the binding of benzothiophenes 3 (up-left), 4 (down-left), 7 (up-right) and 10 (down-right) to the Trypanosoma cruzi Fe-SOD (a) and the human CuZn-SOD (b) enzymes. In the center, an image of the entire enzyme with the compounds binding at the top of the dimer interface is shown. Residues forming the inhibitor binding site are shown. Color scheme: oxygen (red), nitrogen (blue), sulfur (yellow), carbon (pale pink for compound 3, orange for compound 4, blue for compound 7 and magenta for compound 10. For the proteins, one monomer is shown in green and the other in yellow). The ions are shown as spheres. Figures were created with The PyMOL Molecular Graphics System, Version 1.8 Schrödinger, LLC.

\section{CONCLUSIONS}

In conclusion, of the 20 arylaminoketone derivatives tested, in vitro and in vivo experiments allowed us to identify 4 compounds $(3,4,7$ and 10) which showed improved trypanocidal properties and less toxicity. In addition, they present higher activity for treating Chagas disease during acute phase, higher 
curative rates and larger spectrum of action than the reference drug benznidazole. Moreover, none of the compounds included in the toxicological studies were genotoxic or mutagenic. Therefore, they are promising molecules for the development of an easy to synthesize anti-Chagas agent, and this allows us to think that these compounds could be immediately implemented into a step further within the preclinical phase. Finally, it merits mention that due to their different mechanisms of action, combined therapies should be considered for obtaining improved efficiency.

\section{EXPERIMENTAL SECTION}

\section{CHEMISTRY}

General methods. All solvents and chemicals were used as purchased without further purification. Thin layer chromatography (TLC) using silica Alugram SIL G/UV254 (layer: 0.2 mm) (MachereyNagel GmbH\&Co. KG., Düren, Germany) and detection with UV light was used to monitor reactions. Conventional flash column chromatography was carried out with silica gel 60 (0.040_0.063 mm, Merck). Flash column chromatography was developed on a CombiFlash ${ }^{\circ} R_{f}(T E L E D Y N E ~ I S C O$, Lincoln, USA) instrument with Silica RediSep ${ }^{\circledR} R_{f}$ columns. All of the synthesized compounds were chemically characterized by infrared (IR), proton nuclear magnetic resonance $\left({ }^{1} \mathrm{H}\right.$ NMR), carbon nuclear magnetic resonance $\left({ }^{13} \mathrm{C}\right.$ NMR) and elemental microanalyses (CHN). IR spectra were recorded on a Nicolet Nexus FTIR (Thermo, Madison, WI, U.S.) in KBr pellets. Data are reported as vibrational frequency $\left(\mathrm{cm}^{-1}\right)$ and intensity is defined as strong (s), medium (m) and weak (w). In some cases, 2D NMR experiments (COSY, HMBC, HMQC) were carried out for the appropriate peaks assignment. NMR spectra were recorded in DMSO- $\mathrm{d}_{6}$ or $\mathrm{CDCl}_{3}$ solutions on a Bruker 400 Ultrashield instrument. The data are reported as follows: chemical shift in ppm from internal tetramethylsilane (TMS) standard on the $\delta$ scale, multiplicity $(\mathrm{bs}=$ broad singlet, $\mathrm{s}=$ singlet, $\mathrm{d}=$ doublet, $\mathrm{dd}=$ double doublet, $\mathrm{ddd}=$ double double doublet, $\mathrm{t}=$ triplet, $\mathrm{m}=$ multiplet $)$ and coupling constants $(J)$ values given in hertz $(\mathrm{Hz})$. (See supporting information) All compounds were purified to $\geq 96 \%$ purity as determined by elemental microanalysis results obtained on a CHN-900 elemental analyzer (Leco, Tres Cantos, Spain) from vacuum-dried samples. The analytical results for $\mathrm{C}, \mathrm{H}$, and $\mathrm{N}$ were within \pm 0.4 of the theoretical values. 
Melting points (mp) were determined with a Mettler FP82 + FP80 apparatus (Greifensee, Switzerland) and are not corrected.

Synthesis. Compounds 2, 3, 6, 10, 12 and 13 were previously reported. ${ }^{17-19}$

General methodology for the preparation of arylamine Mannich base derivatives (1, 4, 5, 7-9,

11, 14-20). A solution of the substituted methylketone (1.0 eq), the corresponding arylamine (1.0 eq), 1,3-dioxolane $(5 \mathrm{~mL})$ and concentrated $\mathrm{HCl}(1 \mathrm{~mL})$ was heated at reflux. The reaction was followed by TLC until conversion (30 min - 2 h). $\mathrm{NaOH} 2 \mathrm{M}$ was added to basic $\mathrm{pH}$ and the product was extracted with $\mathrm{CH}_{2} \mathrm{Cl}_{2}$. The organic extracts were combined, dried over anhydrous $\mathrm{Na}_{2} \mathrm{SO}_{4}$, filtered and concentrated under reduced pressure. The residue was purified by column chromatography using $\mathrm{CH}_{2} \mathrm{Cl}_{2} /$ methanol 95:5 (v/v) as mobile phase or Automated Flash Chromatography eluting in gradient with $\mathrm{CH}_{2} \mathrm{Cl}_{2} /$ methanol 99:1 (v/v). The desired compounds were precipitated with diethyl ether.

\section{1-(benzo[b]thiophen-3-yl)-3-(4-(4-trifluoromethylphenyl)piperazin-1-yl)propan-1-one}

hydrochloride (1). Yield: 14\%. mp: $209-210^{\circ} \mathrm{C}$. IR (KBr) $v \mathrm{~cm}^{-1}: 2552\left(\mathrm{~s}, v_{\mathrm{HCl}}\right) ; 2458\left(\mathrm{~s}, v_{\mathrm{HCl}}\right) ; 1660$ (s, $\left.v_{\mathrm{C}=\mathrm{O}}\right) ; 1335\left(\mathrm{~s}, v_{\mathrm{C}-\mathrm{F}}\right) ; 1166\left(\mathrm{~s}, v_{\mathrm{C}-\mathrm{F}}\right) ; 1113\left(\mathrm{~s}, v_{\mathrm{C}-\mathrm{F}}\right) ; 1073\left(\mathrm{~s}, \mathrm{v}_{\mathrm{C}-\mathrm{F}}\right) .{ }^{1} \mathrm{H}$ NMR (DMSO-d 6 , $\left.400 \mathrm{MHz}\right) \delta \mathrm{ppm:}$ 11.45-11.26 (bs, $1 \mathrm{H}, \mathbf{H C l})$; 9.15(s, $\left.1 \mathrm{H}, \mathbf{H}_{2}\right) ; 8.61$ (d, $\left.1 \mathrm{H}, \mathbf{H}_{4}, J_{4-5}=7.9 \mathrm{~Hz}\right) ; 8.12$ (d, $\left.1 \mathrm{H}, \mathbf{H}_{7}, J_{7-6}=7.8 \mathrm{~Hz}\right)$;

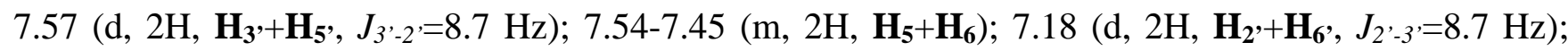

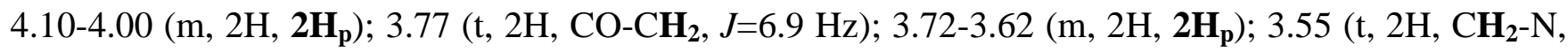
$J=6.8 \mathrm{~Hz}$ ); 3.34-3.19 (m, 4H, $\mathbf{2 H}_{\mathbf{2 p}}+\mathbf{2 H}_{\mathbf{6 p}}$ ). ${ }^{13} \mathrm{C}$ NMR (DMSO-d, $\left.100 \mathrm{MHz}\right) \delta$ ppm: 191.91; 151.97; $140.51 ; 139.36 ; 135.99 ; 133.42 ; 125.89 ; 125.47 ; 124.51: 123.00 ; 114.91$ (2C); 126.30 (2C, q, $J^{3}=4.0$ Hz); 124.78 (q, $J^{1}=268.0 \mathrm{~Hz}$ ); 119.04 (q, $J^{2}=31.5 \mathrm{~Hz}$ ); 50.52 (3C); 44.30 (2C); 34.01. Anal. calcd for $\mathrm{C}_{22} \mathrm{H}_{21} \mathrm{~F}_{3} \mathrm{~N}_{2} \mathrm{OS} . \mathrm{HCl}$ : C 58.08\%, H 4.87\%, N 6.16\%. Found: C 57.81\%, H 4.80\%, N 6.32\%.

\section{1-(5-fluorobenzo[b]thiophen-3-yl)-3-(4-(4-trifluoromethylphenyl)piperazin-1-yl)propan-1-one}

(4). Yield: $26 \%$. mp: $143-144{ }^{\circ} \mathrm{C}$. IR (KBr) $v_{\mathrm{cm}}{ }^{-1}$ : 1664 (s, $\left.v_{\mathrm{C}=\mathrm{O}}\right) ; 1331$ (s, $\left.v_{\mathrm{C}-\mathrm{F}}\right) ; 1243$ (s, $\left.v_{\mathrm{C}-\mathrm{F}}\right) ; 1107$ (s, $\left.v_{\mathrm{C}-\mathrm{F}}\right) .{ }^{1} \mathrm{H} \mathrm{NMR}\left(\mathrm{CDCl}_{3}, 400 \mathrm{MHz}\right) \delta \mathrm{ppm}: 8.48\left(\mathrm{dd}, 1 \mathrm{H}, \mathbf{H}_{4}, J_{4-F}=10.3 \mathrm{~Hz}, J_{4-6}=2.3 \mathrm{~Hz}\right) ; 8.40(\mathrm{~s}, 1 \mathrm{H}$, $\mathbf{H}_{2}$ ); 7.80 (dd, $1 \mathrm{H}, \mathbf{H}_{7}, J_{7-6}=8.8 \mathrm{~Hz}, J_{7-F}=4.8 \mathrm{~Hz}$ ); 7.48 (d, 2H, $\left.\mathbf{H}_{3},+\mathbf{H}_{5}{ }^{\prime}, J_{3^{\prime}-2}{ }^{\prime}=8.6 \mathrm{~Hz}\right) ; 7.20$ (ddd, 1H, $\mathbf{H}_{6}$, $\left.J_{6-F}=8.7 \mathrm{~Hz}, J_{6-7}=8.7 \mathrm{~Hz}, J_{6-4}=2.4 \mathrm{~Hz}\right) ; 6.92\left(\mathrm{~d}, 2 \mathrm{H}, \mathbf{H}_{2},+\mathbf{H}_{6}, J_{2}{ }^{\prime}-3=8.6 \mathrm{~Hz}\right) ; 3.30-3.26(\mathrm{~m}, 4 \mathrm{H}$, 
$\left.\mathbf{2 H}_{3 \mathbf{p}}+\mathbf{2 H}_{\mathbf{5}}\right) ; 3.23\left(\mathrm{t}, 2 \mathrm{H}, \mathrm{CO}-\mathrm{CH}_{2}, J=7.2 \mathrm{~Hz}\right) ; 2.94(\mathrm{t}, 2 \mathrm{H}, \mathrm{CH}-\mathrm{N}, J=7.2 \mathrm{~Hz}) ; 2.72-2.68(\mathrm{~m}, 4 \mathrm{H}$,

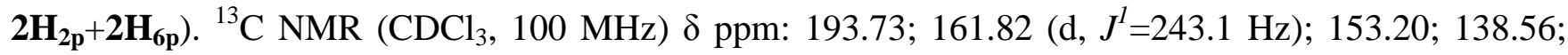
137.91 (d, $\left.J^{3}=10.2 \mathrm{~Hz}\right) ; 134.87 ; 134.84 ; 126.37$ (2C, q, $\left.J^{3}=4.0 \mathrm{~Hz}\right) ; 124.72$ (q, $\left.J^{1}=270.1 \mathrm{~Hz}\right) ; 123.27$ (d, $J^{3}=9.4 \mathrm{~Hz}$ ); 120.55 (q, $\left.J^{2}=32.6 \mathrm{~Hz}\right) ; 114.56$ (d, $\left.J^{2}=25.7 \mathrm{~Hz}\right) ; 114.52$ (2C); 111.62 (d, $\left.J^{2}=25.2 \mathrm{~Hz}\right) ; 53.13$; 52.98 (2C); 47.98 (2C); 37.81. Anal. calcd for $\mathrm{C}_{22} \mathrm{H}_{20} \mathrm{~F}_{4} \mathrm{~N}_{2} \mathrm{OS}$ : C 60.54\%, H 4.62\%, N 6.42\%. Found: C 60.37\%, H 4.30\%, N 6.39\%.

1-(5-fluorobenzo[b]thiophen-3-yl)-3-(4-(4-chlorophenyl)piperazin-1-yl)propan-1-one (5). Yield: 33\%. mp: 156-157 ${ }^{\circ} \mathrm{C}$. IR (KBr) $v \mathrm{~cm}^{-1}: 1660$ (s, $v_{\mathrm{C}=\mathrm{O}}$ ); 1246 (s, $\left.v_{\mathrm{C}-\mathrm{F}}\right) .{ }^{1} \mathrm{H}$ NMR (DMSO-d $\left.6,400 \mathrm{MHz}\right) \delta$ ppm: 9.17 (s, $1 \mathrm{H}, \mathbf{H}_{2}$ ); 8.32 (dd, $\left.1 \mathrm{H}, \mathbf{H}_{4}, J_{4-F}=10.6 \mathrm{~Hz}, J_{4-6}=2.6 \mathrm{~Hz}\right) ; 8.15$ (dd, $1 \mathrm{H}, \mathbf{H}_{7}, J_{7-6}=8.8 \mathrm{~Hz}, J_{7-}$ ${ }_{F}=5.2 \mathrm{~Hz}$ ); 7.88 (ddd, 1H, $\left.\mathbf{H}_{6}, J_{6-F}=9.0 \mathrm{~Hz}, J_{6-7}=8.9 \mathrm{~Hz}, J_{6-4}=2.8 \mathrm{~Hz}\right) ; 7.21$ (d, 2H, $\mathbf{H}_{3},+\mathbf{H}_{5}, J_{3^{\prime}-2},=9.2$ $\mathrm{Hz}) ; 6.93\left(\mathrm{~d}, 2 \mathrm{H}, \mathbf{H}_{2},+\mathbf{H}_{6}, J_{2}{ }_{-3},=9.2 \mathrm{~Hz}\right) ; 3.27$ (t, 2H, CO-CH $\left.\mathbf{H}_{2}, J=7.0 \mathrm{~Hz}\right) ; 3.14-3.07$ (m, 4H, $\mathbf{2 H}_{3 \mathbf{p}}+\mathbf{2 H}_{5 \mathbf{p}}$ ); 2.80 (t, 2H, CH $\left.\mathbf{2}-\mathrm{N}, J=7.2 \mathrm{~Hz}\right) ; 2.62-2.54\left(\mathrm{~m}, 4 \mathrm{H}, \mathbf{2} \mathbf{H}_{2 \mathbf{p}}+\mathbf{2 H}_{6 \mathbf{p}}\right) .{ }^{13} \mathrm{C}$ NMR (DMSO-d, 100 MHz) $\delta$ ppm: 212.89; 160.96 (d, $\left.J^{1}=240.8 \mathrm{~Hz}\right) ; 149.56 ; 142.13 ; 137.43$ (d, $\left.J^{3}=10.5 \mathrm{~Hz}\right) ; 135.06$ (d, $\left.J^{4}=1.3 \mathrm{~Hz}\right) ; 133.64\left(\mathrm{~d}, J^{4}=4.5 \mathrm{~Hz}\right) ; 128.46(2 \mathrm{C}) ; 124.57$ (d, $\left.J^{3}=9.7 \mathrm{~Hz}\right) ; 122.24 ; 116.70(2 \mathrm{C}) ; 113.90$ (d, $\left.J^{2}=25.2 \mathrm{~Hz}\right) ; 109.96\left(\mathrm{~d}, J^{2}=24.9 \mathrm{~Hz}\right) ; 52.64 ; 52.30$ (2C); 47.72 (2C); 36.91. Anal. Calcd. for $\mathrm{C}_{21} \mathrm{H}_{20} \mathrm{ClFN}_{2} \mathrm{OS}$ : C 62.60\%, H 5.00\%, N 6.95\%. Found: C 62.23\%, H 4.63\%, N 6.87\%.

1-(5-fluorobenzo[b]thiophen-3-yl)-3-(4-(4-fluorophenyl)piperazin-1-yl)propan-1-one (7). Yield: 18\%. mp: $156-157{ }^{\circ} \mathrm{C}$. IR (KBr) $v \mathrm{~cm}^{-1}: 1661\left(\mathrm{~s}, v_{\mathrm{C}=\mathrm{O}}\right) ; 1175\left(\mathrm{~s}, v_{\mathrm{C}-\mathrm{F}}\right) ; 1131\left(\mathrm{~s}, v_{\mathrm{C}-\mathrm{F}}\right) .{ }^{1} \mathrm{H}$ NMR $\left(\mathrm{CDCl}_{3}\right.$, $400 \mathrm{MHz}) \delta$ ppm: $8.48\left(\mathrm{dd}, 1 \mathrm{H}, \mathbf{H}_{4}, J_{4-F}=10.4 \mathrm{~Hz}, J_{4-6}=2.6 \mathrm{~Hz}\right) ; 8.39\left(\mathrm{~s}, 1 \mathrm{H}, \mathbf{H}_{2}\right) ; 7.79\left(\mathrm{dd}, 1 \mathrm{H}, \mathbf{H}_{7}, J_{7-}\right.$ $\left.{ }_{6}=8.8 \mathrm{~Hz}, J_{7-F}=4.8 \mathrm{~Hz}\right) ; 7.19\left(\mathrm{ddd}, 1 \mathrm{H}, \mathbf{H}_{6}, J_{6-F}=8.6 \mathrm{~Hz}, J_{6-7}=8.6 \mathrm{~Hz}, J_{6-4}=2.5 \mathrm{~Hz}\right) ; 6.99-6.93(\mathrm{~m}, 2 \mathrm{H}$,

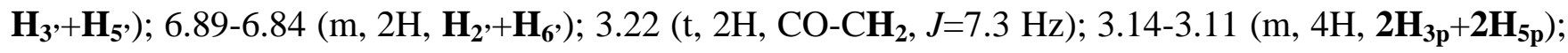
$2.94\left(\mathrm{t}, 2 \mathrm{H}, \mathrm{CH}_{\mathbf{2}}-\mathrm{N}, J=7.3 \mathrm{~Hz}\right) ; 2.71-2.68\left(\mathrm{~m}, \mathbf{4 H}, \mathbf{2} \mathbf{H}_{\mathbf{2}} \mathbf{p}+\mathbf{2 H}_{\mathbf{6 p}}\right) .{ }^{13} \mathrm{C} \mathrm{NMR}\left(\mathrm{CDCl}_{3}, 100 \mathrm{MHz}\right) \delta \mathrm{ppm}:$ 193.82; 161.78 (d, $\left.J^{1}=243.8 \mathrm{~Hz}\right) ; 157.15$ (d, $\left.J^{1}=239.9 \mathrm{~Hz}\right) ; 147.86$ (d, $\left.J^{4}=2.2 \mathrm{~Hz}\right) ; 138.56 ; 137.89$ (d, $\left.J^{3}=10.7 \mathrm{~Hz}\right) ; 135.11\left(\mathrm{~d}, J^{4}=1.6 \mathrm{~Hz}\right) ; 134.84\left(\mathrm{~d}, J^{4}=4.5 \mathrm{~Hz}\right) ; 123.23\left(\mathrm{~d}, J^{3}=9.5 \mathrm{~Hz}\right) ; 117.80\left(2 \mathrm{C}, \mathrm{d}, J^{3}=7.6\right.$ Hz); 115.48 (2C, d, $\left.J^{2}=22.0 \mathrm{~Hz}\right) ; 114.51$ (d, $\left.J^{2}=25.6 \mathrm{~Hz}\right) ; 111.60$ (d, $\left.J^{2}=25.2 \mathrm{~Hz}\right) ; 53.26$ (2C); 53.15; 
50.14 (2C); 37.81. Anal. Calcd. for $\mathrm{C}_{21} \mathrm{H}_{20} \mathrm{~F}_{2} \mathrm{~N}_{2} \mathrm{OS}$ : C 65.27\%, H 5.22\%, N 7.25\%. Found: C 64.94\%, H $5.18 \%$, N 6.88\%.

\section{1-(benzo[b]thiophen-3-yl)-3-(4-benzylpiperazin-1-yl)propan-1-one hydrochloride (8). Yield:}

12\%. mp: 202-203 ${ }^{\circ} \mathrm{C}$. IR (KBr) $v \mathrm{~cm}^{-1}: 2515$ (m, $v_{\mathrm{HCl}}$ ); 2406 (m, $\left.v_{\mathrm{HCl}}\right) ; 1664$ (s, $v_{\mathrm{C}=\mathrm{O}) .}{ }^{1} \mathrm{H}$ NMR (DMSO-d 6 , 400 MHz) $\delta$ ppm: 11.93 (s, 2H, HCl); 9.04 (s, 1H, Hz); 8.60 (d, 1H, H4, J4-5=7.9 Hz); 7.11 (d, 1H, $\left.\mathbf{H}_{7}, J_{7-6}=7.6 \mathrm{~Hz}\right) ; 7.71-7.57\left(\mathrm{~m}, 2 \mathrm{H}, \mathbf{H}_{5}+\mathbf{H}_{\mathbf{6}}\right.$ ); 7.56-7.36 (m, 5H, $\mathbf{H}_{2}, \mathbf{H}_{\mathbf{6}}$ ); 4.36 (s, 2H, CH 2-benzyl);

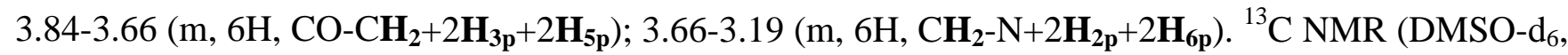
$100 \mathrm{MHz}) \delta$ ppm:. 181.92; 161.21; 150.86; 140.51; 139.36; 135.99; 128.75; 125.87 (2C); 125.47 (2C); 124.98; 124.52 (2C); 123.00; 73.22; 57.70 (3C); 47.33 (2C); 36.99. Anal. Calcd. for $\mathrm{C}_{22} \mathrm{H}_{24} \mathrm{~N}_{2} \mathrm{OS} .2 \mathrm{HCl}$ : C 60.41\%, H 5.99\%, N 6.40\%. Found: C 60.02\%, H 6.08\%, N 6.27\%.

1-(benzo[b]thiophen-3-yl)-3-(4-(3-fluorobenzyl)piperazin-1-yl)propan-1-one hydrochloride (9).

Yield: 12\%. mp: $214-215{ }^{\circ} \mathrm{C}$. IR (KBr) $v \mathrm{~cm}^{-1}: 2525$ (m, $\left.v_{\mathrm{HCl}}\right) ; 2449$ (m, $\left.v_{\mathrm{HCl}}\right) ; 1668\left(\mathrm{~s}, v_{\mathrm{C}=\mathrm{O}}\right) .{ }^{1} \mathrm{H}$ NMR (DMSO-d 6 , 400 MHz) $\delta$ ppm: 11.45-11.26 (bs, 2H, HCl); 9.05(s, 1H, H2); 8.61 (d, 1H, H4, $J_{4-5}=7.7$ $\mathrm{Hz}) ; 8.12\left(\mathrm{~d}, 1 \mathrm{H}, \mathbf{H}_{7}, J_{7-6}=7.8 \mathrm{~Hz}\right) ; 7.66-62\left(\mathrm{~m}, 2 \mathrm{H}, \mathbf{H}_{5}+\mathbf{H}_{6}\right) ; 7.57-7.52\left(\mathrm{~m}, 4 \mathrm{H}, \mathbf{H}_{2},+\mathbf{H}_{4},+\mathbf{H}_{5},+\mathbf{H}_{6}\right.$ ) $) ; 4.41$

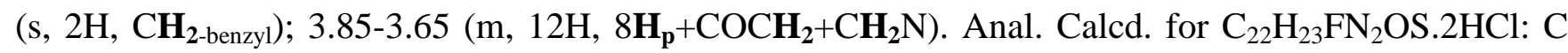
58.02\%, H 5.53\%, N 6.15\%. Found: C 58.40\%, H 5.71\%, N 6.00\%.

\section{1-(thiophen-3-yl)-3-(4-(3-trifluoromethylphenyl)piperazin-1-yl)propan-1-one hydrochloride}

(11). Yield: $18 \%$. mp: $177-178^{\circ} \mathrm{C}$. IR (KBr) $v^{-1} \mathrm{~cm}^{-1}: 2459\left(\mathrm{~m}, v_{\mathrm{HCl}}\right) ; 1682\left(\mathrm{~s}, v_{\mathrm{C}=\mathrm{O}}\right) ; 1166\left(\mathrm{~s}, v_{\mathrm{C}-\mathrm{F}}\right) ; 1120$ $\left(\mathrm{s}, v_{\mathrm{C}-\mathrm{F}}\right) ; 1076\left(\mathrm{~s}, v_{\mathrm{C}-\mathrm{F}}\right) .{ }^{1} \mathrm{H}$ NMR (DMSO-d 6 , $\left.400 \mathrm{MHz}\right) \delta$ ppm: 11.45-11.28 (bs, 1H, HCl); 8.61 (s, 1H, $\left.\mathbf{H}_{2}\right) ; 7.68\left(\mathrm{dd}, 1 \mathrm{H}, \mathbf{H}_{5}, J_{5-4}=4.6 \mathrm{~Hz}, J_{5-2}=2.5 \mathrm{~Hz}\right) ; 7.55\left(\mathrm{~d}, 1 \mathrm{H}, \mathbf{H}_{4}, J_{4-5}=5.0 \mathrm{~Hz}\right) ; 7.47\left(\mathrm{t}, 1 \mathrm{H}, \mathbf{H}_{5}, J_{5-4},=7.9\right.$

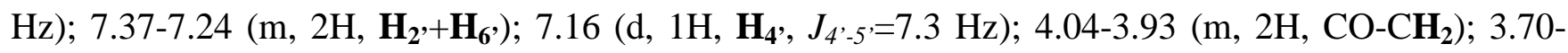
$3.57\left(\mathrm{~m}, 4 \mathrm{H}, 2 \mathbf{H}_{3 \mathbf{p}}+2 \mathbf{H}_{5 \mathbf{p}}\right) ; 3.52-3.43\left(\mathrm{~m}, 2 \mathrm{H}, \mathrm{CH}_{\mathbf{2}}-\mathrm{N}\right) ; 3.28-3.14\left(\mathrm{~m}, 4 \mathrm{H}, 2 \mathbf{H}_{2 \mathbf{p}}+2 \mathbf{H}_{6 \mathbf{p}}\right) .{ }^{13} \mathrm{C} \mathrm{NMR}$ (DMSO-d 6100 MHz) $\delta$ ppm: 190.90; 149.84; 141.07; 134.29; 130.10; 129.92 (q, $J^{2}=30.7$ Hz); 127.76; 126.32; 124.28 (q, $\left.J^{1}=272.0 \mathrm{~Hz}\right) ; 119.22 ; 115.65$ (q, $\left.J^{3}=3.6 \mathrm{~Hz}\right) ; 111.03$ (q, $\left.J^{3}=3.5 \mathrm{~Hz}\right) ; 50.57$ (2C); 50.35; 44.86 (2C); 33.73. Anal. Calcd. for $\mathrm{C}_{18} \mathrm{H}_{19} \mathrm{~F}_{3} \mathrm{~N}_{2} \mathrm{OS} . \mathrm{HCl}$ : C 53.40\%, H 4.98\%, N 6.92\%. Found: C 53.02\%, H 5.02\%, N 6.85\%. 
1-(naphthalen-2-yl)-3-(4-(4-trifluoromethylphenyl)piperazin-1-yl)-propan-1-one (14). Yield:

66\%. mp: $150-151{ }^{\circ} \mathrm{C}$. IR (KBr) $v \mathrm{~cm}^{-1}: 1677\left(\mathrm{~s}, v_{\mathrm{C}=\mathrm{O}}\right) ; 1148\left(\mathrm{~s}, v_{\mathrm{C}-\mathrm{F}}\right) ; 1098\left(\mathrm{~s}, v_{\mathrm{C}-\mathrm{F}}\right) ; 1065\left(\mathrm{~s}, v_{\mathrm{C}-\mathrm{F}}\right) .{ }^{1} \mathrm{H}$ NMR (DMSO-d 6 , 400 MHz) $\delta$ ppm: 8.72 (s, 1H, Hi); 8.14 (d, 1H, H8, $J_{8-7}=7.7$ Hz); 8.03-7.97 (m, 3H,

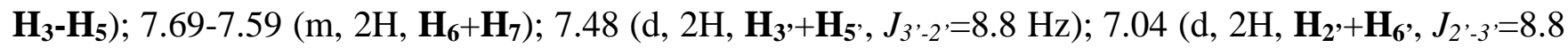

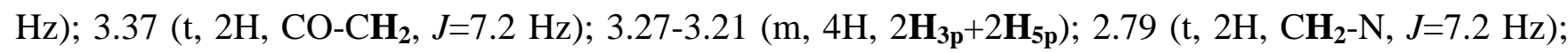

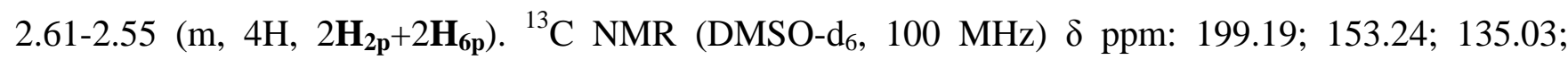
134.00; 132.23; 129.95; 129.60; 128.61; 128.26; 127.64; 126.91; 126.13 (2C, q, $\left.J^{3}=3.8 \mathrm{~Hz}\right) ; 124.99$ (q, $J^{1}=270.1 \mathrm{~Hz}$ ); $123.55 ; 117.78$ (q, $\left.J^{2}=32.0 \mathrm{~Hz}\right) ; 114.12$ (2C); 52.92; 52.41 (2C); 46.96 (2C); 35.81. Anal. Calcd. for $\mathrm{C}_{24} \mathrm{H}_{23} \mathrm{~F}_{3} \mathrm{~N}_{2} \mathrm{O}$ : C 69.89\%, H 5.62\%, N 6.79\%. Found: C 69.82\%, H 5.72\%, N 6.76\%.

1-(naphthalen-2-yl)-3-(4-(4-nitrophenyl)piperazin-1-yl)-propan-1-one (15). Yield: 86\%. mp: 190 $191{ }^{\circ} \mathrm{C}$. IR (KBr) $v \mathrm{~cm}^{-1}: 2806\left(\mathrm{~s}, v_{\mathrm{C}-\mathrm{H}}\right) ; 1674\left(\mathrm{~s}, \mathrm{v}_{\mathrm{C}=\mathrm{O}}\right) .{ }^{1} \mathrm{H}$ NMR (DMSO-d $\left.{ }_{6}, 400 \mathrm{MHz}\right) \delta \mathrm{ppm}: 8.74$ (s, $\left.1 \mathrm{H}, \mathbf{H}_{1}\right) ; 8.14$ (d, 1H, $\left.\mathbf{H}_{\mathbf{8}}, J_{8-7}=7.8 \mathrm{~Hz}\right) ; 8.04\left(\mathrm{~m}, \mathrm{~d}, 2 \mathrm{H}, \mathbf{H}_{3}, \mathbf{H}_{5^{\prime}}, J_{3^{\prime}-2}{ }^{\prime}=9.4 \mathrm{~Hz}\right) ; 8.02-7.98\left(\mathrm{~m}, 3 \mathrm{H}, \mathbf{H}_{3^{-}}\right.$

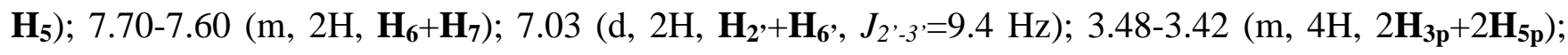
$3.40\left(\mathrm{t}, 2 \mathrm{H}, \mathrm{COCH}_{2}, J=7.2 \mathrm{~Hz}\right) ; 2.80(\mathrm{t}, 2 \mathrm{H}, \mathrm{CH} \mathbf{2}-\mathrm{N}, J=7.2 \mathrm{~Hz}) ; 2.62-2.56\left(\mathrm{~m}, 4 \mathrm{H}, 2 \mathbf{H}_{2 \mathbf{p}}+2 \mathbf{H}_{6 \mathbf{p}}\right) .{ }^{13} \mathrm{C}$ NMR (DMSO-d 6100 MHz) $\delta$ ppm: 199.07; 154.68; 136.75; 134.98; 133.92; 132.19; 129.94; 129.56; 128.57; 128.20; 127.60; 126.86; 125.66 (2C); 123.50; 112.55 (2C); 52.75; 52.24 (2C); 46.23 (2C); 35.71. Anal. Calcd. for $\mathrm{C}_{23} \mathrm{H}_{23} \mathrm{~N}_{3} \mathrm{O}_{3}$ : C 70.93\%, H 5.95\%, N 10.79\%. Found: C 70.99\%, H 5.85\%, N $10.58 \%$.

3-(4-(4-fluorophenyl)piperazin-1-yl)-1-(naphthalen-2-yl) propan-1-one (16). Yield: 15\%. mp: 98-

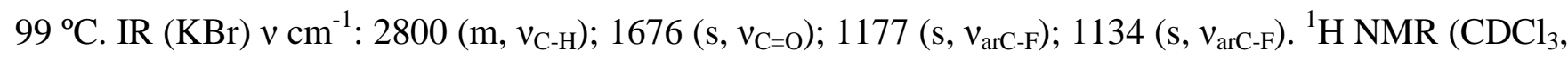
$400 \mathrm{MHz}$ ) $\delta$ ppm: 8.50 (s, 1H, $\mathbf{H}_{1}$ ); 8.04 (dd, 1H, $\left.\mathbf{H}_{\mathbf{8}}, J_{8-7}=8.6 \mathrm{~Hz}, J_{8-6}=1.7 \mathrm{~Hz}\right) ; 7.97$ (d, $1 \mathrm{H}, \mathbf{H}_{3}, J_{3-4}=8.0$ $\mathrm{Hz}) ; 7.91\left(\mathrm{~d}, 1 \mathrm{H}, \mathbf{H}_{5}, J_{5-6}=8.8 \mathrm{~Hz}\right) ; 7.88\left(\mathrm{~d}, 1 \mathrm{H}, \mathbf{H}_{4}, J_{4-3}=8.7 \mathrm{~Hz}\right) ; 7.64-7.54\left(\mathrm{~m}, 2 \mathrm{H}, \mathbf{H}_{\mathbf{6}}+\mathbf{H}_{7}\right) ; 6.97$ (dd,

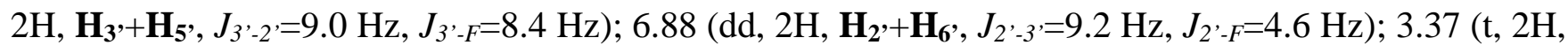
CO-CH $2, J=7.4 \mathrm{~Hz}) ; 3.17-3.12\left(\mathrm{~m}, 4 \mathrm{H}, 2 \mathbf{H}_{3 \mathbf{p}}+2 \mathbf{H}_{5 \mathbf{p}}\right) ; 2.97(\mathrm{t}, 2 \mathrm{H}, \mathrm{CH}-\mathrm{N}, J=7.4 \mathrm{~Hz}) ; 2.75-2.70(\mathrm{~m}, 4 \mathrm{H}$, $\left.2 \mathbf{H}_{2 \mathbf{p}}+2 \mathbf{H}_{\mathbf{6 p}}\right) \cdot{ }^{13} \mathrm{C} \mathrm{NMR}\left(\mathrm{CDCl}_{3}, 100 \mathrm{MHz}\right) \delta \mathrm{ppm}: 198.93 ; 159.17\left(\mathrm{~d}, J^{1}=239.1 \mathrm{~Hz}\right) ; 147.89\left(\mathrm{~d}, J^{4}=2.2\right.$ Hz); 135.60; 134.22; 132.51; 129.71; 129.54; 128.51 (2C); 127.77; 126.81; 123.78; 117.82 (2C, d, 
$\left.J^{3}=7.9 \mathrm{~Hz}\right) ; 115.48\left(2 \mathrm{C}, \mathrm{d}, J^{2}=22.1 \mathrm{~Hz}\right) ; 53.28$ (2C); 53.25; 50.14 (2C); 36.33. Anal. Calcd. for $\mathrm{C}_{23} \mathrm{H}_{23} \mathrm{FN}_{2} \mathrm{O}$ : C 76.22\%, H 6.40\%, N 7.73\%. Found: C 76.46\%, H 6.57\%, N 7.60\%.

\section{1-(benzo[d][1,3]dioxol-5-yl)-3-(4-(4-trifluoromethylphenyl)piperazin-1-yl)propan-1-one}

Yield: 21\%. mp: 107-108 ${ }^{\circ} \mathrm{C}$. IR (KBr) $v \mathrm{~cm}^{-1}: 1669$ (s, $\left.v_{\mathrm{C}=\mathrm{O}}\right) ; 1158\left(\mathrm{~s}, v_{\mathrm{C}-\mathrm{F}}\right) ; 1111\left(\mathrm{~s}, v_{\mathrm{C}-\mathrm{F}}\right) ; 1072\left(\mathrm{~s}, v_{\mathrm{C}-}\right.$ F). ${ }^{1} \mathrm{H}$ NMR (DMSO-d 6 , $\left.400 \mathrm{MHz}\right) \delta$ ppm: $7.65\left(1 \mathrm{H}, \mathrm{d}, \mathbf{H}_{6}, J_{6-7}=8.2 \mathrm{~Hz}\right) ; 7.48\left(\mathrm{~d}, 2 \mathrm{H}, \mathbf{H}_{3^{\prime}},+\mathbf{H}_{5^{\prime}}, J_{3^{\prime}-2},=8.4\right.$

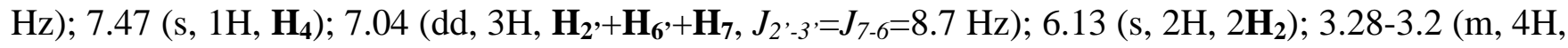
$\left.2 \mathbf{H}_{3 \mathbf{p}}+2 \mathbf{H}_{5 \mathbf{p}}\right) ; 3.16\left(\mathrm{t}, 2 \mathrm{H}, \mathrm{CO}-\mathrm{CH}_{2}, J=7.1 \mathrm{~Hz}\right) ; 2.70\left(\mathrm{t}, 2 \mathrm{H}, \mathrm{CH}_{2}-\mathrm{N}, J=7.1 \mathrm{~Hz}\right) ; 2.59-2.52(\mathrm{~m}, 4 \mathrm{H}$,

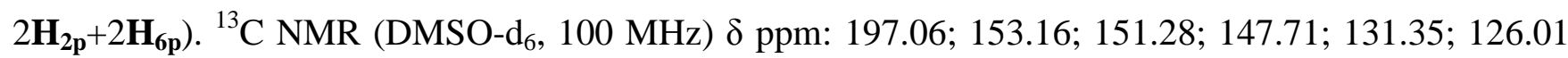
(2C, q, $\left.J^{3}=3.7 \mathrm{~Hz}\right) ; 124.91$ (q, $\left.J^{1}=270.5 \mathrm{~Hz}\right) ; 124.28 ; 117.66$ (q, $J^{2}=32.0 \mathrm{~Hz}$ ); 114.01 (2C); 107.92; 107.33; 101.89; 52.89; 52.29 (2C); 46.85 (2C); 35.45. Anal. Calcd. for $\mathrm{C}_{21} \mathrm{H}_{21} \mathrm{~F}_{3} \mathrm{~N}_{2} \mathrm{O}_{3}$ : C 62.06\%, $\mathrm{H}$ 5.21\%, N 6.89\%. Found: C 62.06\%, H 5.60\%, N 7.03\%.

1-(benzo[d][1,3]dioxol-5-yl)-3-(4-(4-chlorophenyl)piperazin-1-yl)propan-1-one (18). Yield: 20\%. mp: $105-106{ }^{\circ} \mathrm{C}$. IR (KBr) $v \mathrm{~cm}^{-1}: 1675$ (s, $v_{\mathrm{C}=\mathrm{O}}$ ); 1241 (s, $\left.v_{\mathrm{C}-\mathrm{O}}\right) .{ }^{1} \mathrm{H}$ NMR (DMSO-d 6 , $\left.400 \mathrm{MHz}\right) \delta \mathrm{ppm:}$ $7.64\left(\mathrm{dd}, 1 \mathrm{H}, \mathbf{H}_{6}, J_{6-7}=8.2 \mathrm{~Hz}, J_{6-4}=1.3 \mathrm{~Hz}\right) ; 7.46\left(\mathrm{~s}, 1 \mathrm{H}, \mathbf{H}_{4}\right) ; 7.20\left(\mathrm{~d}, 2 \mathrm{H}, \mathbf{H}_{3^{\prime}}, \mathbf{H}_{5^{\prime}}, J_{3^{\prime}-2}=8.9 \mathrm{~Hz}\right) ; 7.02$ (d, $\left.1 \mathrm{H}, \mathbf{H}_{7}, J_{7-6}=8.2 \mathrm{~Hz}\right) ; 6.92\left(\mathrm{~d}, 2 \mathrm{H}, \mathbf{H}_{2}, \mathbf{H}_{6^{\prime}}, J_{2^{\prime}-3}{ }^{\prime}=8.9 \mathrm{~Hz}\right) ; 6.12\left(\mathrm{~s}, 2 \mathrm{H}, 2 \mathbf{H}_{2}\right) ; 3.14\left(\mathrm{t}, 2 \mathrm{H}, \mathrm{CO}-\mathbf{C H}_{2}\right.$, $J=7.1 \mathrm{~Hz}) ; 3.11-3.05\left(\mathrm{~m}, 4 \mathrm{H}, 2 \mathbf{H}_{3 \mathbf{p}}+2 \mathbf{H}_{5 \mathrm{p}}\right) ; 2.69\left(\mathrm{t}, 2 \mathrm{H}, \mathrm{CH}_{2}-\mathrm{N}, J=7.1 \mathrm{~Hz}\right) ; 2.57-2.51(\mathrm{~m}, 4 \mathrm{H}$, $2 \mathbf{H}_{2 \mathbf{p}}+2 \mathbf{H}_{6 \mathbf{p}}$ ). ${ }^{13} \mathrm{C}$ NMR (DMSO-d 6 , $\left.100 \mathrm{MHz}\right) \delta$ ppm: 197.20; 151.35; 149.78; 147.78; 131.40; 128.55 (2C); 124.38; 122.22; 116.74 (2C); 108.00; 107.38; 101.97; 52.98; 52.49 (2C); 47.95 (2C); 35.52. Anal. Calcd. for $\mathrm{C}_{20} \mathrm{H}_{21} \mathrm{ClN}_{2} \mathrm{O}_{3}$ : C 64.43\%, H 5.68\%, N 7.51\%. Found: C 64.61\%, H 5.86\%, N 7.40\%.

1-(benzo[d][1,3]dioxol-5-yl)-3-(4-(4-nitrophenyl)piperazin-1-yl)propan-1-one (19). Yield: $50 \%$. mp: $164-165^{\circ} \mathrm{C}$. IR (KBr) $v \mathrm{~cm}^{-1}: 1665$ (s, $\left.v_{\mathrm{C}=0}\right) ; 1241$ (s, $\left.v_{\mathrm{C}-\mathrm{o}}\right) .{ }^{1} \mathrm{H}$ NMR (DMSO-d 6 , $\left.400 \mathrm{MHz}\right) \delta \mathrm{ppm}$ : $8.04\left(\mathrm{~d}, 2 \mathrm{H}, \mathbf{H}_{3}, \mathbf{H}_{5}, J_{3^{\prime}-2},=9.4 \mathrm{~Hz}\right) ; 7.65\left(\mathrm{dd}, 1 \mathrm{H}, \mathbf{H}_{6}, J_{6-7}=8.2 \mathrm{~Hz}, J_{6-4}=1.4 \mathrm{~Hz}\right) ; 7.47\left(\mathrm{~s}, 1 \mathrm{H}, \mathbf{H}_{4}\right) ; 7.06-$ $7.00\left(\mathrm{~m}, 3 \mathrm{H}, \mathbf{H}_{7}+\mathbf{H}_{2},+\mathbf{H}_{6}\right.$ ); $6.13\left(\mathrm{~s}, 2 \mathrm{H}, 2 \mathbf{H}_{2}\right) ; 3.46-3.40\left(\mathrm{~m}, 4 \mathrm{H}, 2 \mathbf{H}_{3 \mathbf{p}}+2 \mathbf{H}_{5 \mathbf{p}}\right) ; 3.16\left(\mathrm{t}, 2 \mathrm{H}, \mathrm{CO}-\mathrm{CH}_{2}\right.$, $J=7.0 \mathrm{~Hz}$ ); $2.70\left(\mathrm{t}, 2 \mathrm{H}, \mathrm{CH}_{2}-\mathrm{N}, J=7.1 \mathrm{~Hz}\right) ; 2.57-2.51\left(\mathrm{~m}, 4 \mathrm{H}, 2 \mathbf{H}_{2 \mathbf{p}}+2 \mathbf{H}_{6 \mathbf{p}}\right) .{ }^{13} \mathrm{C}$ NMR (DMSO-d, 100 MHz) $\delta$ ppm: 197.08; 154.66; 151.33; 147.75; 136.75; 131.35; 125.64 (2C); 124.35; 112.54 (2C); 
107.98; 107.38; 101.94; 52.78; 52.17 (2C); 46.21 (2C); 35.42. Anal. Calcd. for $\mathrm{C}_{20} \mathrm{H}_{21} \mathrm{~N}_{3} \mathrm{O}_{5}$ : C 62.65\%, H 5.52\%, N 10.96\%. Found: C 62.29\%, H 5.43\%, N 10.61\%.

1-(benzo[d][1,3]dioxol-5-yl)-3-(4-(4-fluorophenyl)piperazin-1-yl)propan-1-one (20). Yield: 19\%.

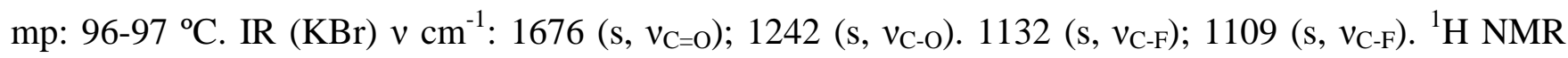
$\left(\right.$ DMSO-d $\left._{6}, 400 \mathrm{MHz}\right) \delta$ ppm: $7.65\left(\mathrm{~d}, 1 \mathrm{H}, \mathbf{H}_{6}, J_{6-7}=8.0 \mathrm{~Hz}\right) ; 7.47\left(\mathrm{~s}, 1 \mathrm{H}, \mathbf{H}_{4}\right)$; 7.07-6.99 (m, 3H, $\mathbf{H}_{3},+\mathbf{H}_{5},+\mathbf{H}_{7}$ ); 6.93 (dd, 2H, $\left.\mathbf{H}_{2},+\mathbf{H}_{6}{ }^{\prime}, J_{2}{ }^{\prime}-3,=8.9 \mathrm{~Hz}, J_{2}{ }^{\prime}-F=4.6 \mathrm{~Hz}\right) ; 6.13\left(\mathrm{~s}, 2 \mathrm{H}, 2 \mathbf{H}_{2}\right) ; 3.14$ (t, 2H, CO$\left.\mathrm{CH}_{2}, J=7.0 \mathrm{~Hz}\right) ; 3.08-2.99\left(\mathrm{~m}, 4 \mathrm{H}, 2 \mathbf{H}_{3 \mathbf{p}}+2 \mathbf{H}_{5 \mathrm{p}}\right) ; 2.69\left(\mathrm{t}, 2 \mathrm{H}, \mathrm{C} \mathbf{H}_{2}-\mathrm{N}, J=7.1 \mathrm{~Hz}\right) ; 2.59-2.52(\mathrm{~m}, 4 \mathrm{H}$, $2 \mathbf{H}_{2 \mathbf{p}}+2 \mathbf{H}_{\mathbf{6 p}}$ ). ${ }^{13} \mathrm{C}$ NMR (DMSO-d $\left.6,100 \mathrm{MHz}\right) \delta \mathrm{ppm}: 197.10 ; 155.84$ (d, $J^{1}=235.4 \mathrm{~Hz}$ ); $151.26 ; 147.82$ (d, $\left.J^{4}=1.9 \mathrm{~Hz}\right) ; 147.71 ; 131.35 ; 124.28 ; 116.92$ (2C, d, $\left.J^{3}=7.5 \mathrm{~Hz}\right) ; 115.10$ (2C, d, $\left.J^{2}=21.8 \mathrm{~Hz}\right) ; 107.92$; 107.32; 101.89; 52.94; 52.59 (2C); 48.85 (2C); 35.49. Anal. Calcd. for $\mathrm{C}_{20} \mathrm{H}_{21} \mathrm{FN}_{2} \mathrm{O}_{3}$ : C 67.40\%, H 5.94\%, N 7.86\%. Found: C 67.30\%, H 6.04\%, N 7.75\%.

Calculation of molecular properties. The drug-likeness of the compounds was estimated with Osiris, using the stand-alone DataWarrior program. ${ }^{22}$ The information about the methods used to evaluate each property is available on the program web site http://www.openmolecules.org.

\section{BIOLOGY}

\section{In vitro Trypanocidal Evaluation}

Parasite strain culture. Epimastigote and trypomastigote forms: Epimastigote assays. The epimastigote forms of $T$. cruzi SN3 strain (IRHOD/CO/2008/SN3, DTU I) that were isolated from the household triatomine Rhodnius prolixus (from Guajira, Colombia). ${ }^{53}$ Epimastigotes of T. cruzi Arequipa strain (MHOM/Pe/2011/ Arequipa, DTU V) isolated from a human and Tulahuen strain (TINF/CH/1956/Tulahuen, DTU VI) were cultivated in vitro using trypanosome liquid medium (MTL) containing $10 \%$ inactivated fetal bovine serum and maintained at $28^{\circ} \mathrm{C}$ in an air atmosphere, in Roux flasks (Corning, USA) of $75 \mathrm{~cm}^{2}$ surface area, as described in previous studies. ${ }^{54}$ The epimastigote forms transformed into metacyclic forms by metacyclogenesis triggered by culturing a 5-day-old epimastigote forms that had been harvested by centrifuging $(7000 \mathrm{~g})$ at $10^{\circ} \mathrm{C}$ for $10 \mathrm{~min}$. Next the parasites were incubated at $28^{\circ} \mathrm{C}$ for $2 \mathrm{~h}$ (density of $5 \times 10^{8}$ cells/mL) in TAU medium (190 mM NaCl, 
$17 \mathrm{mM} \mathrm{KCl}, 2 \mathrm{mM} \mathrm{MgCl}, 2 \mathrm{mM} \mathrm{CaCl}$, $8 \mathrm{mM}$ phosphate buffer, $\mathrm{pH}$ 6.0). The parasites were then incubated at a dilution of 1:100 (final concentration of epimastigotes: $5 \times 10^{6}$ cells/mL) at $28{ }^{\circ} \mathrm{C}$ f or 96 $\mathrm{h}$ in TAU3AAG medium (TAU supplemented with $10 \mathrm{mM}$ L-proline, $50 \mathrm{mM}$ L-sodium glutamate, 2 mM L-sodium aspartate and $10 \mathrm{mM}$ D-glucose) in $25 \mathrm{~mL}$ flasks with a layer culture medium no more than $1 \mathrm{~cm}$ in deep. ${ }^{55}$

Trypomastigote Forms assays. The activity (parasite-reduction \%) was compared to control with the method described above ${ }^{54}$, with certain modifications in our lab. The test of drug action against T. cruzi used Balb/c albino mouse blood collected during peak parasitemia (day 7). The infected blood was diluted using uninfected mouse blood at a concentration of $4 \times 10^{6}$ trypomastigotes $/ \mathrm{mL}$. Then, in RPMI 1640 medium-GIBCO ( 2 x 106 trypomastigotes/mL), a dilution was made to 1:2. Stock solutions of the compounds were prepared in DMSO. The $\mathrm{IC}_{50}$ values were calculated using, samples of infected blood, adding each drug to wells in a 96-microwell plate for a final $200 \mu \mathrm{L}$ volume for drug concentrations of 1, 10, 25, 50, and $100 \mu \mathrm{M}$., and the plates were then incubated for $24 \mathrm{~h}$ at 4 - to $8{ }^{\circ} \mathrm{C}$. Each experiment was replicated three times (OLYMPUS CX41) and the parasites were counted in the Neubauer chamber. Cytotoxicity and Cell Culture Tests. Vero cells (EACC number 84113001) originally extracted from monkey kidney, were cultured for two days in RPMI (Gibco), supplemented with 10\% inactivated fetal bovine serum in $95 \%$ humidified air, $5 \% \mathrm{CO}_{2}$ at $37^{\circ} \mathrm{C}$. The cytotoxicity test was performed for Vero cells following a methodology described previously. ${ }^{54}$ Flow cytometry was used to determine cell viability after $72 \mathrm{~h}$ of treatment. Propidium iodide solution $(100 \mathrm{mg} / \mathrm{mL})$ was added at $100 \mu \mathrm{L} /$ well and incubated at $28^{\circ} \mathrm{C}$ for $10 \mathrm{~min}$ in darkness. Then, fluorescein diacetate $(100 \mathrm{ng} / \mathrm{mL})$ was added at 100 $\mu \mathrm{L} /$ well and incubated using the same conditions. The cells were collected by centrifuging (400 $\mathrm{g}$ for 10 min), and finally the precipitate was washed using PBS (phosphate buffered saline). Flow cytometry was performed with a FACSVantage flow cytometer (Becton Dickinson), and the percentage of viability was computed in comparison to control. The $\mathrm{IC}_{50}$ was calculated with linear-regression analysis employing the $K_{c}$ values corresponding to the concentrations used ( 0.1 to $\left.100 \mu \mathrm{M}\right)$. 
In Vitro Activity. Epimastigote Forms Assays (Extracellular Forms). The compounds obtained and BZN (the reference drug), dissolved in DMSO (Panreac, Barcelona, Spain) at a 0.01\% (v/v) concentration and assayed, proved nontoxic to the parasites and not inhibitory to their growth, according to a procedure reported on a previous work. ${ }^{56}$ The compounds, at doses of $100,50,25,10,1,0.5,0.25$, and $0.1 \mu \mathrm{M}$ were added to the culture medium. For each compound, the effects against $T$. cruzi epimastigote forms were assayed at $72 \mathrm{~h}$ with a hemocytometric chamber (Neubauer). The antitrypanosomatid effect is expressed as the $\mathrm{IC}_{50}$. That is, the concentration needed for $50 \%$ growth inhibition, determined by linear regression with the $K_{c}$ values of the concentrations used.

Amastigote Assays (Intracellular Forms). Vero cells grown as indicated above in RPMI medium (Gibco), were inoculated at $1 \times 10^{4}$ cells/well in 24-well microplates (Nunc) that had rounded coverslips and cultured 2 days. Then the Vero cells were infected for 24 h in vitro using metacyclic forms at a 10:1 ratio. After the removal of non-phagocytic parasites by washing, the drugs $(100,50,25,10,1,0.50 .25$ and $0.1 \mu \mathrm{M}$ ) were added. Vero cells were incubated with the drugs at $37^{\circ} \mathrm{C}$ for $72 \mathrm{~h}$ in $5 \% \mathrm{CO}_{2}$. The activity of the drugs was evaluated based on the number of amastigotes in treated as well as untreated cultures, in preparations that were methanol-fixed and Giemsa-stained. The number of amastigotes was estimated analyzing 200 host cells in randomly taken microscopic fields. The anti trypanosomal effect was expressed as the $\mathrm{IC}_{50}$.

\section{In vitro genotoxicity screening}

Bacteria. S. typhimurium TA1535/pSK1002 was obtained from the German Collection for Microorganisms and Cell cultures (DSMZ). Chemicals. DMSO, dextrose, NaCl, ampicillin, onitrophenol- $\beta$-D-galactopyranoside (ONPG), $\mathrm{Na}_{2} \mathrm{CO}_{3}, \mathrm{Na}_{2} \mathrm{HPO}_{4} 2 \mathrm{H}_{2} \mathrm{O}, \mathrm{NaH}_{2} \mathrm{PO}_{4} \cdot \mathrm{H}_{2} \mathrm{O}, \mathrm{MgSO}_{4} \cdot 7 \mathrm{H}_{2} \mathrm{O}$, $\mathrm{KCl}, \quad \beta$-mercaptoethanol and sodium dodecyl sulphate were obtained from Sigma-Aldrich; Bactotryptone was obtained from BD; and rat S9 mix (Mutazyme) was obtained from Moltox.

Reagents preparation for SOS/umu test. TGA culture medium was prepared dissolving $10 \mathrm{~g}$ bactotryptone, $2 \mathrm{~g}$ dextrose and $5 \mathrm{~g} \mathrm{NaCl}$ in $1 \mathrm{~L}$ of water and sterilizing during 30 minutes at $121{ }^{\circ} \mathrm{C}$. Bbuffer was prepared dissolving $20.18 \mathrm{~g} \mathrm{Na}_{2} \mathrm{HPO}_{4} \cdot 2 \mathrm{H}_{2} \mathrm{O}$, 5.5 g NaH $\mathrm{PO}_{4} \cdot \mathrm{H}_{2} \mathrm{O}, 0.75 \mathrm{~g} \mathrm{KCl,} 0.25 \mathrm{~g}$ 
$\mathrm{MgSO}_{4} .7 \mathrm{H}_{2} \mathrm{O}, 1.0 \mathrm{~g} \mathrm{SDS}, 2.7 \mathrm{~mL} \beta$-mercaptoethanol in $1 \mathrm{~L}$ water adjusting $\mathrm{pH}$ value to 7. Stop reagent $\left(\mathrm{Na}_{2} \mathrm{CO}_{3} 1 \mathrm{M}\right)$ was prepared dissolving $106 \mathrm{~g}$ of $\mathrm{Na}_{2} \mathrm{CO}_{3}$ in $1 \mathrm{~L}$ water. Phosphate buffer (for ONPG dissolution) was prepared dissolving $1.086 \mathrm{~g} \mathrm{Na}_{2} \mathrm{HPO}_{4} \cdot 2 \mathrm{H}_{2} \mathrm{O}$ and $0.538 \mathrm{~g} \mathrm{NaH} \mathrm{PO}_{4} \cdot \mathrm{H}_{2} \mathrm{O}$ in $100 \mathrm{~mL}$ water and adjusting $\mathrm{pH}$ value to 7. ONPG solution was prepared dissolving $45 \mathrm{mg}$ ONPG in $10 \mathrm{~mL}$ phosphate buffer.

SOS/umu test. The SOS/umu test was carried out according to the method of Oda et al. (1985) and Reifferscheid et al. (1991), with some modifications. ${ }^{57,58}$ The test strain S. typhimurium TA1535/pSK1002 was used. It was pre-incubated overnight in TGA medium with ampicillin $(50 \mu \mathrm{g} / \mathrm{mL})$ by shaking in an incubator at $37^{\circ} \mathrm{C}$ in order to obtain exponentially growing bacteria. The test was performed in the absence and the presence of external metabolic activation system (rat S9 mix) in order to determine the possible genotoxic effects of any metabolite. In each test performed, negative and positive controls were included. DMSO was used as solvent control, and 4-nitroquinoline- $N$-oxide (4NQO) and 2-aminofluorene (2-AF) were used as positive controls with and without of S9 mix.

Test procedure was as follows: firstly, each compound tested was dissolved in DMSO at $40 \mathrm{mg} / \mathrm{mL}$ and 11 serial 1/2 dilutions were prepared in a 96-well plate (plate A; final volume in each well was 10 $\mu \mathrm{L}$ ). Next, $70 \mu \mathrm{L}$ of water were added to each well. In another two 96-well plates (plates B; one for the test with S9 and the other without S9), $10 \mu \mathrm{L}$ S9 mix or $10 \mu \mathrm{L}$ PBS, were added, respectively, followed by the addition of $25 \mu \mathrm{L}$ of each previously prepared compound. Finally, $90 \mu \mathrm{L}$ of exponentially growing bacteria was added and incubated during 4 hours by shaking at $37^{\circ} \mathrm{C}$. After the incubation period, absorbance at $600 \mathrm{~nm}$ was measured in order to evaluate toxicity on S. typhimurium TA1535/pSK1002. Toxicity was calculated as follows:

Survival percentage $=($ A600 for each concentration tested/media A600 for negative control $) * 100$ Afterwards, for the determination of $\beta$-galactosidase activity, in two new 96-well plates (plates C), $150 \mu \mathrm{L}$ of ONPG solution were added to each well and $30 \mu \mathrm{L}$ of the contents of each well of plates B were transferred to these plates C. Both plates were incubated for 30 minutes by shaking at $28{ }^{\circ} \mathrm{C}$, avoiding direct light exposure. After the incubation period, $120 \mu \mathrm{L}$ of stop reagent were added and the 
reaction was stopped. Absorbance $(420 \mathrm{~nm})$ was then measured immediately, and $\beta$-galactosidase activity (relative units; RU) was calculated as follows:

$\beta$-galactosidase enzymatic units $=$ A420 for each concentration tested/A600 for each concentration tested

Finally, the induction factor (IF) was calculated as follows:

$\mathrm{IF}=\beta$-galactosidase $\mathrm{RU}$ for each concentration tested/media $\beta$-galactosidase $\mathrm{RU}$ for negative control, where: media $\beta$-galactosidase RU for negative control = media A420 for negative control/media A600 for negative control

In the same way, $\beta$-galactosidase relative units were calculated for both positive controls, and the test was only considered valid if the positive controls reached an induction factor $\geq 2$ under the given test conditions.

Thus, a compound was consider genotoxic, as it induces the induction of the umu operon, when in any of the conditions studied (with or without metabolic activation), the induction factor was $\geq 2$ at non cytotoxic concentrations (bacteria survival percentage $\geq 80 \%$ ), presenting a dose-response relationship. Wells in which compound precipitation was observed, were discarded from analysis.

\section{Infectivity Assay}

Vero cells were cultured under the same conditions for two days. The, cells were then infected in vitro with $T$. cruzi metacyclic forms, at a $10: 1$ ratio. Immediately after infection, the drugs $\left(\mathrm{IC}_{25}\right.$ concentrations) were added, followed by incubation at $37^{\circ} \mathrm{C}$ for $12 \mathrm{~h}$ in $5 \% \mathrm{CO}_{2}$. After removal of the drugs and nonphagocytosed parasites by washing, the infected cultures were grown in fresh medium for 10 day. ${ }^{41}$ Every 48 h, fresh culture medium was added. The activity of the drugs was determined from the \% of infected cells, the number of amastigotes per infected cell, and the number of trypomastigotes in the medium, both in treated as well as untreated cultures, and in methanol-fixed as well as Giemsastained preparations. A determination was made every $48 \mathrm{~h}$ of the mean number of amastigotes per infected cell and the \% of infected cells by examining 200 host cells in randomly taken microscopic 
fields. The trypomastigotes in the medium were counted every $48 \mathrm{~h}$ in a hemocytometric chamber (Neubauer).

\section{In Vivo Trypanocidal Activity Assay}

For the following purposes, in the in vivo stage, experimental tests were performed: i) to assess the influence that the compounds exerted on the parasitemia levels post- treatment by a Neubauer chamber count for 40 days as an acute-phase marker; ii) to provide a measure of the parasitemia reactivation following immunosuppression as a chronic-phase marker; iii) to compare the levels of the chronic and acute phases of Ig-G using ELISA as an immune-response indicator; and iv) for detection of the parasite's presence using PCR in target organs.

Mice Infection and Treatment. The mice were handled following the international guide for biomedical research using experimental animals and the experiment was approved by the ethics board of the University of Granada (Spain). Groups of six female BALB/c albino mice 8 to 10 weeks old and weighing 25 to 30 g, were kept under standard conditions and given free access to standard chow and water. The mice were infected intraperitoneally using $5 \times 10^{5}$ blood trypomastigotes (T. cruzi Arequipa strains) from the blood of mice previously infected. These animals were split in the three groups: I, untreated infected mice constituted the positive control group; II, infected mice treated using the reference drug made up the BZN group; and III, infected mice treated using the compounds under investigation comprised the study group. The tested compounds were administered beginning on the day 7 after confirmation of the infection, and dosages of 50 and $100 \mathrm{mg} / \mathrm{kg}$ body mass per day were given orally on 5 alternating days (day 7 to 15 pi). In each mouse, peripheral blood was taken from the mandibular vein (5 $\mu \mathrm{L}$ samples) and this was diluted in $495 \mu \mathrm{L}$ PBS solution (1:100). The circulating parasites were counted in a Neubauer chamber every 3 days for $40 \mathrm{~d}$ (acute phase). The number of bloodstream forms detected was expressed in parasites/mL.

Immunosuppression Induced by Cyclophosphamide- and Cure Assessment. At day 90 pi, the groups in which the parasitemia levels had significantly fallen, (irrespective of the treatment the mice received) and could not be detected by microscopic examination of fresh blood, were subjected to 3 cycles of 
immunosuppression using CP (cyclophosphamide monohydrate ISOPAC ${ }^{\circledR}$ ) as follows: 4 days consecutively on which the mice were given 1 intraperitoneal injection/day (dosage $200 \mathrm{mg} / \mathrm{kg} \cdot \mathrm{w} / \mathrm{day}$ ), and 3 days off. The effectiveness of this immunosuppression technique for evaluating cryptic infection was corroborated by the mortality rate of nearly $100 \%$ in chronically untreated mice and/or by the high parasitemia rate. The parasitemia was assessed within 1 week after the last injection of CP, following the procedure explained above for the acute phase in order to quantify the trypomastigote forms in blood as the reactivation rate. The mice were finally bled by heart puncture under gaseous anesthesia $\left(\mathrm{CO}_{2}\right)$. Blood was incubated for 2 hours at $37{ }^{\circ} \mathrm{C}$ and then over night at $4^{\circ} \mathrm{C}$ in order to allow clotting. Subsequently, the serum was obtained after centrifuging the supernatant twice at 1000 and $2700 \mathrm{~g}$, consecutively. The serum was used for ELISA and biochemical analysis as explained further on in this paper. Thanks to our previous in vivo studies, we observed that the tropism of T. cruzi strain (Arequipa) occurs in the following organs: adipose, brain, heart, esophagus, stomach, bone marrow, muscle and lung. Therefore these 8 target organs were harvested and immediately flushed free of blood by gentle infusion of pre-warmed PBS for the purpose of avoid contamination of collected tissue with blood parasites. Next, they were used for DNA extraction, as explained below. In addition, spleens were weighed to evaluate inflammation of these organs in different groups of mice.

ELISA Tests. Fe-SOD excreted from the parasite, cultured and processed as described by LopezCéspedes et al. ${ }^{59}$ was used as antigen. Circulating antibodies in serum against $T$. cruzi, from day 40 to day 120 post-infection (including sera post-immunosuppression), were qualitatively and quantitatively assessed using ELISA. The serum was centrifuged from whole blood and diluted in PBS to 1:80. The absorbance was read at $492 \mathrm{~nm}$ using a microplate reader (Sunrise, TECAN). All samples, in triplicate, were analyzed in polystyrene microtiter plates. For calculating the cutoff value, the mean and standard deviations of the optical density of the negative control sera were used.

PCR and DNA Extraction. The organs to be studied were thawed and then ground using a PotterElvehjem for purification using Wizard ${ }^{\circledR}$ Genomic DNA Purification Kit (Promega). The PCR was conducted with two primers from our laboratory (unpublished data), based on the published SOD 
(superoxide dismutase) sequence of T. cruzi CL Brenner (GenBank accession No. XM_808937); this amplifies a fragment pertaining to T. cruzi SOD gene b of c. 300 pb. The amplification was performed in Thermal Cycler TM MyCycler thermocycler (BioRad).

\section{Studies of the action mechanism of}

Superoxide Dismutase (SOD) Inhibition Studies. T. cruzi epimastigotes cultured as indicated above were centrifuged and collected. After the suspension of the pellet in $3 \mathrm{~mL}$ of STE buffer $(0.25 \mathrm{M}$ sucrose, $25 \mathrm{mM}$ Tris- $\mathrm{HCl}, 1 \mathrm{M}$ EDTA, $\mathrm{pH}$ 7.8), the cells were broken up by ultrasonication (three cycles) at $60 \mathrm{~W}$ every $30 \mathrm{~s}$. Following 1500-g centrifugation of the homogenate at $4^{\circ} \mathrm{C}$ for 5 min and, the pellet was washed in ice-cold STE buffer three times and centrifuged ( $2500 \mathrm{~g}$ at $4^{\circ} \mathrm{C}$ for $\left.10 \mathrm{~min}\right)$ The supernatant was collected to determine its protein concentration using the Bradford method. ${ }^{60}$ The activities of Fe-SOD and CuZn-SOD (iron and copper-zinc superoxide dismutases) (were determined by the method of Beyer and Fridovich, ${ }^{61}$ to measure the extent to which nitrobluetetrazolium (NBT) was reduced by superoxide ions. To each cuvette, the following was added: $1.5 \mathrm{~mL}$ of Triton X-100 1\% (v/v)], $2 \mathrm{~mL}$ of NBT (1.41 mg, $10 \mathrm{~mL}^{-1}$ ), and $845 \mu \mathrm{L}$ of stock solution [3 mL of L-methionine (300 mg, $\left.10 \mathrm{~mL}^{-1}\right)$, as well as $30 \mu \mathrm{L}$ of the homogenate fraction of the parasite, $10 \mu \mathrm{L}$ riboflavin $(0.44 \mathrm{mg}, 10$ $\mathrm{mL}^{-1}$ ), and an equivalent volume of the compound solution. For each compound, 5 concentrations were used: 1 to $100 \mu \mathrm{M}$. For the control experiment, the volume was raised to $1000 \mu \mathrm{L}$ using $50 \mathrm{mM}$ potassium phosphate buffer ( $\mathrm{pH} 7.8)$, while $30 \mu \mathrm{L}$ of the homogenate fraction of the parasite were added to the mixtures that contained the compounds. A spectrophotometer was used to measure the absorbance $\left(\mathrm{A}_{0}\right)$, at $560 \mathrm{~nm}$. Each cuvette was placed under lamp light for 10 min with constant stirring, and a measurement was made of the absorbance $\left(A_{1}\right)$. The substrates, coenzymes, and human CuZn-SOD used in these tests were from Sigma Chemical Co. The data were submitted to the Newman-Keuls test. ${ }^{62}$

Metabolite excretion. Cultures of epimastigotes of T. cruzi Arequipa strain at a starting concentration of $5 \times 10^{5}$ cells $/ \mathrm{mL}$ ) received the $\mathrm{IC}_{25}$ dosage of each compound (excepting control cultures). After $72 \mathrm{~h}$ of incubation for at $28^{\circ} \mathrm{C}$ the cells underwent centrifugation (400 g) for $10 \mathrm{~min}$. After supernatant collection, the excreted metabolites were determined by ${ }^{1} \mathrm{H}$ NMR; using sodium 2,2-dimethyl-2- 
silapentane-5-sulphonate as the reference signal, and chemical shifts were expressed in ppm. The chemical shifts used for the identification of the respective metabolites were in line with those that some of the co-authors have reported previously. ${ }^{62}$

\section{Mutagenicity studies}

Bacteria. S. typhimurium histidine auxotrophic strains TA 98, TA 100, TA 102, TA 1535 and TA 1537 were obtained from Moltox (Trinova, Biochem GmbH). Chemicals. S9 mix (Mutazyme) was obtained from Moltox. All the reagents were obtained from Sigma-Aldrich.

\section{Bacterial reverse mutation test (Ames test).}

The bacterial reverse mutation test, so-called the Ames test, was performed following the recommendations of the OECD guideline 471 and using the pre-incubation version. ${ }^{63}$ Bacteria were exposed to 5 soluble and non-toxic concentrations of the test compound in absence or presence of an external enzymatic metabolizing system (S9 Mix). Briefly, $100 \mu \mathrm{L}$ of bacterial suspension were mixed with $50 \mu \mathrm{L}$ of each test compound solution and $500 \mu \mathrm{L}$ of PBS or S9 mix. After $1 \mathrm{~h}$ of incubation at 37 ${ }^{\circ} \mathrm{C}, 2 \mathrm{~mL}$ of molten top agar supplemented with histidine and biotin traces (i.e. $0.05 \mathrm{mM}$ each) were added to the mix, vortexed, and poured onto glucose minimal agar plates. Plates where then incubated for $48 \mathrm{~h}$ at $37^{\circ} \mathrm{C}$ before histidine revertants colonies were counted. For-nitro-o-phenylendiamine (NPD) and sodium azide (NaAZ) were used as positive controls in the absence of S9 mix, while 2aminoantracene (2-AA) and 2-aminofluorene (2-AF) were used in the presence of S9 mix. DMSO was used as negative control. Experiments were performed using technical triplicates.

\section{Docking study}

The compounds were designed with the program Ghemical, ${ }^{64}$ using the protonation state at $\mathrm{pH} 7.4$ determined by the chemicalize web server (http://www.chemicalize.org/). For the enzymes, the PDB structures with codes 4DVH and 2GPC were used for the mitochondrial and cytosolic T. cruzi Fe-SOD proteins, respectively; and the PDB structure with code 2C9V was used for the human CuZn-SOD. Their protonation states at pH 7.4 were obtained with the program PDB2PQR. ${ }^{65}$ Afterwards, Gasteiger charges for both proteins and ligand were added with Autodock. ${ }^{66}$ The docking study was performed 
with the Autodock4.0 program, using the Lamarckian genetic algorithm (LGA). ${ }^{67}$ In a first step, a grid was defined containing the whole protein. After the binding site was determined, docking runs generating 100 poses were carried out for each protein/ligand, using a smaller grid center on the binding site.

\section{ASSOCIATED CONTENT}

Supporting Information. ${ }^{1} \mathrm{H}$ and ${ }^{13} \mathrm{C}$ NMR spectra of newly synthesized compounds. ${ }^{1} \mathrm{H}$ NMR spectra of the excretion products obtained after centrifugation of T. cruzi culture supernatants of epimastigotes. “This material is available free of charge via the Internet at http://pubs.acs.org.”

\section{AUTHOR INFORMATION}

\section{Corresponding Author}

* Silvia Pérez-Silanes. Phone: (+34)948425600; e-mail: sperez@unav.es.

* Manuel Sánchez Moreno. Phone (+34)958242369; e-mail msanchem@ugr.es.

\section{Author Contributions}

†.M. and C.J. contributed equally.

\section{Funding Sources}

This work has been carried out with the financial support of Fundación Caja Navarra (Project n. 70314), the Institute of Tropical Health from the University of Navarra (Project API-2011/01), and financial support from the former Spanish Ministry of Science and Innovation (MICINN) and now from the Ministry of Economy and Competitiveness (MINECO) (project Consolider Ingenio CSD2010-00065).

\section{Notes}

The authors declare no competing financial interest.

\section{ACKNOWLEDGMENT}


The authors are grateful to Ms. María Garrido, Ms. Celia Goñi, Ms. Carmen Elizalde and Mr. Iulen Lizarraga for their kind help. MJ is indebted to the University of Navarra for a grant. AA thanks the Ministerio de Economía y Competitividad ('Ramón y Cajal’ programme, 2013) of the Spanish Government for personal support. R.M-E. is grateful for a FPU Grant (FPU14/01537) from the Ministry of Education of Spain.

\section{ABBREVIATIONS}

2-AF, 2-aminofluorene; 4-NQO, 4-nitroquinoline-N-oxide; BZN, benznidazol; CD, Chagas Disease; CP, Cyclophosphamide monohydrate; DMSO, Dimethylsulfoxide; ELISA, enzyme linked immunosorbent assay; IR, Infrared; mp, melting point; NFX, nifurtimox; NTD, Neglected tropical diseases; NMR, Nuclear magnetic resonance; PCR, Polymerase Chain Reaction; pi, post infection; SOD, Superoxide Dismutase; Fe-SOD, Iron Superoxide Dismutase; CuZn-SOD, Cupper Zinc Superoxide Dismutase; TMS, Tetramethylsilane; TLC, Thin layer chromatography; TPP, Target product profile; T. cruzi, Trypanosoma cruzi; Nitroblue tetrazolium (NBT).

\section{REFERENCES}

(1) Romanha, A. J.; Castro, S. L.; Soeiro Mde, N.; Lannes-Vieira, J.; Ribeiro, I.; Talvani, A.; Bourdin, B.; Blum, B.; Olivieri, B.; Zani, C.; Spadafora, C.; Chiari, E.; Chatelain, E.; Chaves, G.; Calzada, J. E.; Bustamante, J. M.; Freitas-Junior, L. H.; Romero, L. I.; Bahia, M. T.; Lotrowska, M.; Soares, M.; Andrade, S. G.; Armstrong, T.; Degrave, W.; Andrade Zde, A. In vitro and in vivo experimental models for drug screening and development for Chagas disease. Mem. Inst. Oswaldo Cruz 2010, 105, 233-238.

(2) Rassi, A., Jr.; Rassi, A.; Marin-Neto, J. A. Chagas disease. Lancet 2010, 375, 1388-1402.

(3) Montgomery, S. P.; Starr, M. C.; Cantey, P. T.; Edwards, M. S.; Meymandi, S. K. Neglected parasitic infections in the United States: Chagas Disease. Am. J. Trop. Med. Hyg. 2014, 90, 814-818. (4) Jackson, Y.; Varcher Herrera, M.; Gascon, J. Economic crisis and increased immigrant mobility: new challenges in managing Chagas disease in Europe. Bull. W. H. O. 2014, 92, 771-772. 
(5) Requena-Méndez , A.; Aldasoro, E.; de Lazzari, E.; Sicuri, E.; Brown, M.; Moore, D. A. J.;

Gascon, J.; Muñoz, J. Prevalence of Chagas Disease in latin-american migrants living in Europe: A systematic review and meta-analysis. PLoS Negl. Trop. Dis. 2015, 9(2), e0003540.

(6) WHO. Chagas disease (American trypanosomiasis).

http://www.who.int/mediacentre/factsheets/fs340/en/

(7) De Andrade, A. L.; Zicker, F.; de Oliveira, R. M.; Almeida Silva, S.; Luquetti, A.; Travassos, L. R.; Almeida, I. C.; de Andrade, S. S.; de Andrade, J. G.; Martelli, C. M. Randomised trial of efficacy of benznidazole in treatment of early Trypanosoma cruzi infection. Lancet 1996, 348, 1407-1413.

(8) Prata, A. Clinical and epidemiological aspects of Chagas disease. Lancet Infect. Dis. 2001, 1, 92100.

(9) Rojo, G.; Castillo, C.; Duaso, J.; Liempi, A.; Droguett, D.; Galanti, N.; Maya, J. D.; LópezMuñoz, R.; Kemmerling, U. Toxic and therapeutic effects of nifurtimox and benznidazol on Trypanosoma cruzi ex vivo infection of human placental chorionic villi explants. Acta Trop. 2014, 132, 112-118.

(10) Bermudez, J.; Davies, C.; Simonazzi, A.; Real, J. P.; Palma, S. Current drug therapy and pharmaceutical challenges for chagas disease. Acta Trop. 2016, 156, 1-16.

(11) DNDi. Target product profile. http://www.dndi.org/diseases-projects/chagas/chagas-targetproduct-profile/ February 8, 2016.

(12) Ribeiro, I.; Sevcsik, A. M.; Alves, F.; Diap, G.; Don, R.; Harhay, M. O.; Chang, S.; Pecoul, B. New, improved treatments for Chagas disease: from the R\&D pipeline to the patients. PLoS Negl. Trop. Dis. 2009, 3, e484.

(13) Hotez, P. J.; Bottazzi, M. E.; Franco-Paredes, C.; Ault, S. K.; Periago, M. R. The neglected tropical diseases of latin america and the caribbean: a review of disease burden and distribution and a roadmap for control and elimination. PLoS Negl. Trop. Dis. 2008, 2, e300.

(14) Swinney, D. C.; Anthony, J. How were new medicines discovered? Nat. Rev. Drug Discov. 2011, 10, 507-519. 
methods into efficient pipelines. Drug Discovery Today. 2014, 19, 637-644.

(16) Oficialdegui, A. M.; Martinez, J.; Perez, S.; Heras, B.; Irurzun, M.; Palop, J. A.; Tordera, R.; Lasheras, B.; del Rio, J.; Monge, A. Design, synthesis and biological evaluation of new 3-[(4aryl)piperazin-1-yl]-1-arylpropane derivatives as potential antidepressants with a dual mode of action: serotonin reuptake inhibition and 5-HT1A receptor antagonism. Il Farmaco 2000, 55, 345-353.

$$
\text { Martinez-Esparza, J.; Oficialdegui, A. M.; Perez-Silanes, S.; Heras, B.; Orus, L.; Palop, J. A.; }
$$

Lasheras, B.; Roca, J.; Mourelle, M.; Bosch, A.; Del Castillo, J. C.; Tordera, R.; Del Rio, J.; Monge, A. New 1-aryl-3-(4-arylpiperazin-1-yl)propane derivatives, with dual action at 5-HT1A serotonin receptors and serotonin transporter, as a new class of antidepressants. J. Med. Chem. 2001, 44, 418-428.

(18) Orus, L.; Perez-Silanes, S.; Oficialdegui, A. M.; Martinez-Esparza, J.; Del Castillo, J. C.; Mourelle, M.; Langer, T.; Guccione, S.; Donzella, G.; Krovat, E. M.; Poptodorov, K.; Lasheras, B.; Ballaz, S.; Hervias, I.; Tordera, R.; Del Rio, J.; Monge, A. Synthesis and molecular modeling of new 1aryl-3-[4-arylpiperazin-1-yl]-1-propane derivatives with high affinity at the serotonin transporter and at 5-HT(1A) receptors. J. Med. Chem. 2002, 45, 4128-4139.

(19) Perez-Silanes, S.; Berrade, L.; Garcia-Sanchez, R. N.; Mendoza, A.; Galiano, S.; PerezSolorzano, B. M.; Nogal-Ruiz, J. J.; Martinez-Fernandez, A. R.; Aldana, I.; Monge, A. New 1-aryl-3substituted propanol derivatives as antimalarial agents. Molecules. 2009, 14, 4120-4135.

(20) Berrade, L.; Aisa, B.; Ramirez, M. J.; Galiano, S.; Guccione, S.; Moltzau, L. R.; Levy, F. O.; Nicoletti, F.; Battaglia, G.; Molinaro, G.; Aldana, I.; Monge, A.; Perez-Silanes, S. Novel benzo[b]thiophene derivatives as new potential antidepressants with rapid onset of action. J. Med. Chem. 2011, 54, 3086-3090.

(21) Mendoza, A.; Perez-Silanes, S.; Quiliano, M.; Pabon, A.; Galiano, S.; Gonzalez, G.; Garavito, G.; Zimic, M.; Vaisberg, A.; Aldana, I.; Monge, A.; Deharo, E. Aryl piperazine and pyrrolidine as antimalarial agents. Synthesis and investigation of structure-activity relationships. Exp. Parasitol. 2011, 128, 97-103. 
chemistry aware data visualization and analysis. J. Chem. Inf. Model. 2015, 55, 460-473.

(23) Gonzalez, P. M., C.; Rodriguez-Gonzalez, I.; Hitos, A. B.; Rosales, M. J.; Reina, M.; Diaz, J. G.;

Gonzalez-Coloma, A.; Sanchez-Moreno, M. In vitro activity of C20-diterpenoid alkaloid derivatives in promastigotes and intracellular amastigotes of Leishmania infantum. Int. J. Antimicrob. Agents. 2005, 25, 136-141.

(24) Nwaka, S.; Besson, D.; Ramirez, B.; Maes, L.; Matheeussen, A.; Bickle, Q.; Mansour, N. R.; Yousif, F.; Townson, S.; Gokool, S.; Cho-Ngwa, F.; Samje, M.; Misra-Bhattacharya, S.; Murthy, P. K.; Fakorede, F.; Paris, J. M.; Yeates, C.; Ridley, R.; Van Voorhis, W. C.; Geary, T. Integrated dataset of screening hits against multiple neglected disease pathogens. PLoS Negl. Trop. Dis. 2011, 5, e1412. (25) da Silva, C. F.; Batista, M. M.; Batista Dda, G.; de Souza, E. M.; da Silva, P. B.; de Oliveira, G. M.; Meuser, A. S.; Shareef, A. R.; Boykin, D. W.; Soeiro Mde, N. In vitro and in vivo studies of the trypanocidal activity of a diarylthiophene diamidine against Trypanosoma cruzi. Antimicrob. Agents Chemother. 2008, 52, 3307-3314.

(26) Rodriques Coura, J.; de Castro, S. L. A critical review on Chagas disease chemotherapy. Mem. Inst. Oswaldo Cruz. 2002, 97, 3-24.

(27) Rivera, J.; Hillis, L. D.; Levine, B. D. Reactivation of cardiac Chagas' disease in acquired immune deficiency syndrome. Am. J. Cardiol. 2004, 94, 1102-1103.

(28) Caldas, S.; Santos, F. M.; de Lana, M.; Diniz, L. F.; Machado-Coelho, G. L.; Veloso, V. M.; Bahia, M. T. Trypanosoma cruzi: acute and long-term infection in the vertebrate host can modify the response to benznidazole. Exp. Parasitol. 2008, 118, 315-323.

(29) Murcia, L.; Carrilero, B.; Ferrer, F.; Roig, M.; Franco, F.; Segovia, M. Success of benznidazole chemotherapy in chronic Trypanosoma cruzi-infected patients with a sustained negative PCR result. Eur. J. Clin. Microbiol. Infect. Dis. 2016, 35, 1819-1827. 
Salomone, O. A. Risk progression to chronic Chagas cardiomyopathy: influence of male sex and of parasitaemia detected by polymerase chain reaction. Heart. 2003, 89 1186-1190.

(31) Williams, J. T., Mubiru, J. N., Schlabritz-Loutsevitch, N. E., Rubicz, R. C., VandeBerg, J. L.,

Dick, E. J., Hubbard, G. B. Polymerase chain reaction detection of Trypanosoma cruzi in Macaca fascicularis using archived tissues. Am. J. Trop. Med. Hyg. 2009, 81, 228-234.

(32) Francisco A., J. S., Lewis M. D., White K. L., Shackleford D. M. ,Chen G., Saunders J., OsunaCabello M., Read K. D., Charman S. A., Chatelain E., Kelly J. M. Nitroheterocyclic drugs cure experimental Trypanosoma cruzi infections more effectively in the chronic stage than in the acute stage. Sci. Rep. 2016, 6, 35351.

(33) Britto, C., Cardoso, M. A., Marques, P., Fernandes, O., Morel, C. M. Polymerase chain reaction detection: new insights into the diagnosis of chronic Chagas disease. Mem. Ins. Oswaldo Cruz. 1999, 94, 305-306.

(34) Maes, L.; Vanden Berghe, D.; Germonprez, N.; Quirijnen, L.; Cos, P.; De Kimpe, N.; Van Puyvelde, L. In vitro and in vivo activities of a triterpenoid saponin extract (PX-6518) from the plant Maesa balansae against visceral leishmania species. Antimicrob. Agents Chemother. 2004, 48, 130-136. (35) Germonprez, N.; Maes, L.; Van Puyvelde, L.; Van Tri, M.; Tuan, D. A.; De Kimpe, N. In vitro and in vivo anti-leishmanial activity of triterpenoid saponins isolated from Maesa balansae and some chemical derivatives. J. Med. Chem. 2005, 48, 32-37.

(36) Hunter, W. N.; Alphey, M. S.; Bond, C. S.; Schuttelkopf, A. W. Targeting metabolic pathways in microbial pathogens: oxidative stress and anti-folate drug resistance in trypanosomatids. Biochem. Soc. Trans. 2003, 31, 607-610.

(37) Piacenza, L.; Zago, M. P.; Peluffo, G.; Alvarez, M. N.; Basombrio, M. A.; Radi, R. Enzymes of the antioxidant network as novel determiners of Trypanosoma cruzi virulence. Int. J. Parasitol. 2009, 39, 1455-1464. 

approach to therapy of african sleeping sickness, chagas' disease, and leishmaniasis. Amino Acids 2007, 33, 359-366.

(39) Flohe, L. The trypanothione system and its implications in the therapy of trypanosomatid diseases. Int. J. Med. Microbiol. 2012, 302, 216-220.

(40) Sánchez-Moreno, M.; Gómez-Contreras, F.; Navarro, P.; Marín, C.; Olmo, F.; Yunta, M. J. R.; Sanz, A. M.; Rosales, M. J.; Cano, C.; Campayo, L. Phthalazine derivatives containing imidazole rings behave as Fe-SOD inhibitors and show remarkable anti-T. cruzi activity in immunodeficient-mouse mode of infection. J. Med. Chem. 2012, 55, 9900-9913.

(41) Sanchez-Moreno, M.; Sanz, A. M.; Gomez-Contreras, F.; Navarro, P.; Marin, C.; RamirezMacias, I.; Rosales, M. J.; Olmo, F.; Garcia-Aranda, I.; Campayo, L.; Cano, C.; Arrebola, F.; Yunta, M. J. In vivo trypanosomicidal activity of imidazole- or pyrazole-based benzo[g]phthalazine derivatives against acute and chronic phases of Chagas disease. J. Med. Chem. 2011, 54, 970-979.

(42) Sanz, A. M.; Gomez-Contreras, F.; Navarro, P.; Sanchez-Moreno, M.; Boutaleb-Charki, S.; Campuzano, J.; Pardo, M.; Osuna, A.; Cano, C.; Yunta, M. J.; Campayo, L. Efficient inhibition of iron superoxide dismutase and of Trypanosoma cruzi growth by benzo[g]phthalazine derivatives functionalized with one or two imidazole rings. J. Med. Chem. 2008, 51, 1962-1966.

(43) Villagran, M. E.; Marin, C.; Rodriguez-Gonzalez, I.; De Diego, J. A.; Sanchez-Moreno, M. Use of an iron superoxide dismutase excreted by Trypanosoma cruzi in the diagnosis of Chagas disease: seroprevalence in rural zones of the state of Queretaro, Mexico. Am. J. Trop. Med. Hyg. 2005, 73, 510516.

(44) Ginger, M. L. Trypanosomatid biology and euglenozoan evolution: new insights and shifting paradigms revealed through genome sequencing. Protist 2005, 156, 377-392.

(45) Cazzulo, J. J. Aerobic fermentation of glucose by trypanosomatids. FASEB J. 1992, 6, 31533161. 
Develop. Biol. 2001, 12, 449-457.

(47) Muñoz, I. G. M., J. F.; Becana, M.; Montoya, G. The crystal structure of an eukaryotic iron superoxide dismutase suggests intersubunit cooperation during catalysis. Protein Sci. 2005, 14, 387-394.

(48) Tellez-Valencia, A. O.-I., V.; Hernandez-Santoyo, A.; Perez-Montfort, R.; Costas, M.;

Rodriguez-Romero, A.; Lopez-Calahorra, F.; Tuena De Gomez-Puyou, M.; Gomez-Puyou, A. . Inactivation of triosephosphate isomerase from Trypanosoma cruzi by an agent that perturbs its dimer interface. J. Mol. Biol. 2004, 341, 1355-1365.

(49) Kershaw, N. M. W., G. S.; Sharma, R.; Antonyuk, S. V.; Strange, R. W.; Berry, N. G.; O'Neill, P. M.; Hasnain, S. S. X-ray crystallography and computational docking for the detection and development of protein-ligand interactions. Curr. Med. Chem. 2013, 20, 569-575.

(50) Antonyuk, S. S., R. W.; Hasnain, S. S. Structural discovery of small molecule binding sites in Cu-Zn human superoxide dismutase familial amyotrophic lateral sclerosis mutants provides insights for lead optimization. J. Med. Chem. 2010, 53, 1402-1406.

(51) Ray, S. S. N., R. J.; Brown, R. H., Jr.; Lansbury, P. T., Jr. Small-molecule-mediated stabilization of familial amyotrophic lateral sclerosis-linked superoxide dismutase mutants against unfolding and aggregation. Proc. Nat.l Acad. Sci. U.S.A. 2005, 102, 3639-3644.

(52) Bhatia, N. K. S., A.; Katyal, N.; Jain, N.; Khan, M. A.; Kundu, B.; Deep, S. Curcumin binds to the pre-fibrillar aggregates of $\mathrm{Cu} / \mathrm{Zn}$ superoxide dismutase (SOD1) and alters its amyloidogenic pathway resulting in reduced cytotoxicity. Biochim. Biophys. Acta. 2015, 1854, 426-436.

(53) Tellez-Meneses, J.; Mejia-Jaramillo, A. M.; Triana-Chavez, O. Biological characterization of Trypanosoma cruzi stocks from domestic and sylvatic vectors in Sierra Nevada of Santa Marta, Colombia. Acta. Trop. 2008, 108, 26-34.

(54) Olmo, F.; Marin, C.; Clares, M. P.; Blasco, S.; Albelda, M. T.; Soriano, C.; Gutierrez-Sanchez, R.; Arrebola-Vargas, F.; Garcia-Espana, E.; Sanchez-Moreno, M. Scorpiand-like azamacrocycles 
prevent the chronic establishment of Trypanosoma cruzi in a murine model. Eur. J. Med. Chem. 2013, 70, 189-198.

(55) Cardoso, J.; Soares, M. J. In vitro effects of citral on trypanosoma cruzi metacyclogenesis. Mem. Inst. Oswaldo Cruz. 2010, 105, 1026-1032.

(56) Júnior, C. O. A., R. O.; Rezende, C. A.; Costa, C. F. D.; H.Silva; Hyaric, M. L.; Pontes, A. P.; Alves, R. J.; Romanha, A. J.; Almeida., M. V. Tripanocidal activity of lipophilic diamines and amino alcohols. Biomed. Pharmacother. 2010, 109, 624-626.

(57) Oda, Y. N., S.; Oki, I.; Kato, T.; Shinagawa, H. Evaluation of the new system (umu-test) for the detection of environmental mutagens and carcinogens. Mutat. Res. 1985, 147, 219-229.

(58) Reifferscheid, G. H., J.; Oda, Y.; Zahn, R. K. A microplate version of the SOS/umu-test for rapid detection of genotoxins and genotoxic potentials of environmental samples. Mutat. Res. 1991, 253, 215-222.

(59) López-Céspedes, Á. V., E.; Álvarez, K. B.; Diego, J. A. d.; Hernández-Montiel, H. L.; Saldaña, C.; Sānchez-Moreno, M.; Marín, C. Trypanosoma cruzi: seroprevalence detection in suburban population of Santiago de Querétaro (Mexico). Sci. World J. 2012, 2012, Article ID 914129, 7 pages. (60) Bradford, M. M. A rapid and sensitive method for the quantitation of microgram quantities of protein utilizing the principle of protein-dye binding. Anal. Biochem. 1976, 72, 248-254.

(61) Beyer, W. F., Jr.; Fridovich, I. Assaying for superoxide dismutase activity: some large consequences of minor changes in conditions. Anal. Biochem. 1987, 161, 559-566.

(62) Fernández-Becerra, C.; Sánchez-Moreno, M.; Osuna, A.; Opperdoes, F. R. Comparative aspects of energy metabolism in plant trypanosomatids. J. Euk. Micro. 1997, 44, 523-529.

(63) OECD Guidelines for testing of chemicals Nos. 471 Bacterial reverse mutation test.; 1997.

(64) Hassinen, T. P., M. New energy terms for reduced protein models implemented in an off-lattice force field. J. Comput. Chem. 2001, 22, 1229-1242. 
expanding and upgrading automated preparation of biomolecular structures for molecular simulations. Nuc. Acids Res. 2007, 35, W522-W525.

(66) Morris, G. M. H., R.; Lindstrom, W.; Sanner, M. F.; Belew, R. K.; Goodsell, D. S.; Olson, A. J. . AutoDock4 and AutoDockTools4: Automated docking with selective receptor flexibility. J. Comput. Chem. 2009, 30, 2785-2791.

(67) Huey, R. M., G. M.; Olson, A. J.; Goodsell, D. S. A semiempirical free energy force field with charge-based desolvation. J. Comput. Chem. 2007, 28, 1145-1152.

Table 1. Proposed TPP for Chagas disease modified from $\mathrm{DNDi}^{11}$

\begin{tabular}{|c|c|c|}
\hline TPP & Acceptable & Ideal \\
\hline Target population & Chronic & Chronic and acute \\
\hline Adult/children & Adult & All \\
\hline Clinical efficacy & $\begin{array}{l}\text { Superiority to BZN in all endemic } \\
\text { regions }\end{array}$ & $\begin{array}{l}\text { Superiority to BZN to different } \\
\text { phases of disease (acute and } \\
\text { chronic; reactivated patients) }\end{array}$ \\
\hline $\begin{array}{l}\text { Active against resistant } \\
\text { strains }\end{array}$ & Not necessary & $\begin{array}{l}\text { Active against nitrofuran- and } \\
\text { nitroimidazole-resistant } T \text {. cruzi } \\
\text { strains }\end{array}$ \\
\hline Safety & Superiority to BZN & Superior to BZN \\
\hline Contraindications & Pregnancy/lactation & None \\
\hline Precautions & $\begin{array}{l}\text { No genotoxicity } \\
\text { No significant pro-arrhythmic } \\
\text { potential }\end{array}$ & $\begin{array}{l}\text { No genotoxicity } \\
\text { No teratogenicity } \\
\text { No significant pro-arrhythmic }\end{array}$ \\
\hline
\end{tabular}




\begin{tabular}{|l|l|l|}
\hline & & potential \\
\hline Presentation & Oral & Oral \\
\hline Dosing regime & $\begin{array}{l}\text { Comparable to systemic antifungal } \\
\text { treatments }\end{array}$ & Once daily for 30 days \\
\hline Stability & 3 years, climate zone IV & 5 years, climate zone IV \\
\hline
\end{tabular}


Table 2. Relationship of synthesized compounds.

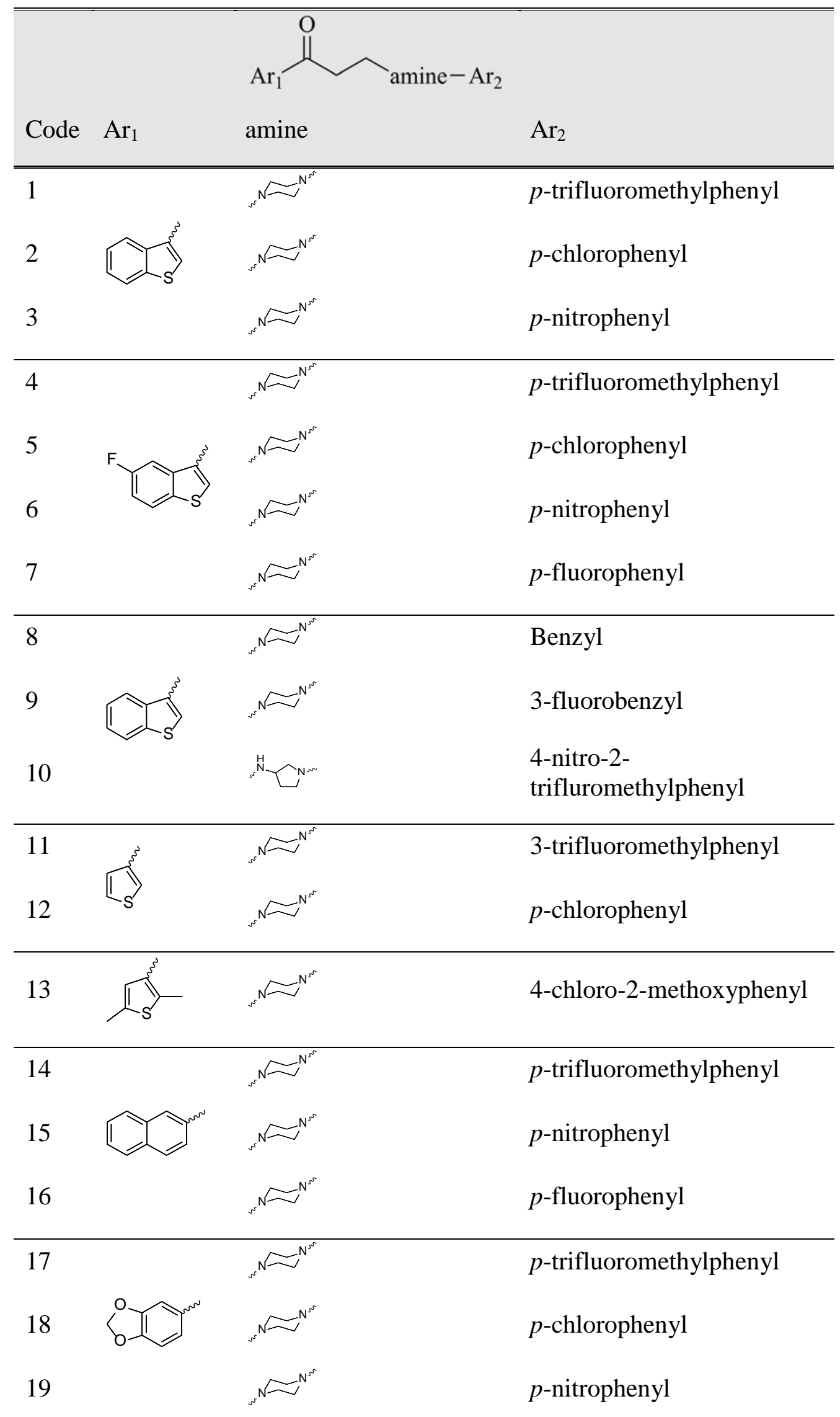


${ }^{N} \sim^{N^{r}} \quad p$-fluorophenyl 
Table 3. Molecular properties of the new compounds calculated with the DataWarrior program. ${ }^{22}$

\begin{tabular}{|c|c|c|c|c|c|c|}
\hline Comp. & $\mathrm{MW}^{\mathrm{a}}$ & $\operatorname{clog} \mathrm{P}^{\mathrm{b}}$ & $\operatorname{clog} S^{c}$ & PSA $^{\mathrm{d}}$ & $\mathrm{HBA}^{\mathrm{e}}$ & $\mathrm{HBD}^{\mathrm{f}}$ \\
\hline 1 & 371.3 & 3.2 & -5.1 & 51.8 & 3 & 0 \\
\hline 2 & 356.4 & 3.1 & -5.1 & 51.8 & 3 & 0 \\
\hline 3 & 362.4 & 4.1 & -4.8 & 97.6 & 6 & 0 \\
\hline 4 & 437.4 & 3.6 & -5.4 & 51.8 & 3 & 0 \\
\hline 5 & 404.9 & 3.5 & -5.4 & 51.8 & 3 & 0 \\
\hline 6 & 372.8 & 3.6 & -5.1 & 97.6 & 6 & 0 \\
\hline 7 & 455.4 & 3.7 & -5.0 & 51.8 & 3 & 0 \\
\hline 8 & 383.4 & 1.1 & -3.8 & 51.8 & 3 & 0 \\
\hline 9 & 384.9 & 4.3 & -4.1 & 51.8 & 3 & 0 \\
\hline 10 & 386.5 & 3.9 & -6.3 & 106.4 & 6 & 1 \\
\hline 11 & 389.4 & 2.2 & -3.8 & 51.8 & 3 & 0 \\
\hline 12 & 429.4 & 4.0 & -3.7 & 51.8 & 3 & 0 \\
\hline 13 & 395.5 & 1.8 & -4.7 & 61.0 & 4 & 0 \\
\hline 14 & 402.9 & 4. 4 & -5.5 & 23.5 & 3 & 0 \\
\hline 15 & 406.4 & 3.8 & -5.2 & 69.4 & 6 & 0 \\
\hline 16 & 412.4 & 4.9 & -5.0 & 23.5 & 3 & 0 \\
\hline 17 & 413.5 & 1.9 & -4.6 & 42.0 & 5 & 0 \\
\hline 18 & 454.9 & 4.5 & -4.5 & 42.0 & 5 & 0 \\
\hline 19 & 436.5 & 4.6 & -4.3 & 87.8 & 8 & 0 \\
\hline 20 & 463.5 & 2.0 & -4.1 & 42.0 & 5 & 0 \\
\hline
\end{tabular}

\footnotetext{
${ }^{\mathrm{a}}$ Total Molecular Weight (g/mol). ${ }^{\mathrm{b}}$ Logarithm of the partition coefficient between $n$-octanol and water. ${ }^{c}$ Logarithm of the solubility measured in mol/L. ${ }^{\mathrm{d}}$ Polar Surface Area $\left(\AA^{2}\right)$. ${ }^{\mathrm{e}}$ Number of hydrogen-bond acceptors. ${ }^{\mathrm{f}}$ Number of hydrogen-bond donors.
} 
Table 4. In vitro activity and toxicity for the 20 arylaminoketone derivatives on extra- and intracellular forms of Trypanosoma cruzi strains.

\begin{tabular}{|c|c|c|c|c|c|c|c|c|c|c|}
\hline \multirow[t]{2}{*}{ Comp. } & \multicolumn{3}{|c|}{$\begin{array}{l}\text { Activity } \mathrm{IC}_{50}(\mu \mathrm{M})^{\mathrm{a}} \\
\text { T. cruzi Arequipa strain }\end{array}$} & \multicolumn{3}{|c|}{$\begin{array}{l}\text { Activity } \mathrm{IC}_{50}(\mu \mathrm{M})^{\mathrm{a}} \\
\text { T. cruzi Tulahuen strain }\end{array}$} & \multicolumn{3}{|c|}{$\begin{array}{l}\text { Activity } \mathrm{IC}_{50}(\mu \mathrm{M})^{\mathrm{a}} \\
\text { T. cruzi SN3 strain }\end{array}$} & \multirow{2}{*}{$\begin{array}{l}{ }^{b} \text { Vero cells } \\
\text { toxicity } \\
\mathrm{IC}_{50}(\mu \mathrm{M})\end{array}$} \\
\hline & $\begin{array}{l}\text { Epim. } \\
\text { forms }\end{array}$ & $\begin{array}{l}\text { Amast. } \\
\text { forms }\end{array}$ & $\begin{array}{l}\text { Trypom. } \\
\text { forms }\end{array}$ & $\begin{array}{l}\text { Epim. } \\
\text { forms }\end{array}$ & $\begin{array}{l}\text { Amast. } \\
\text { forms }\end{array}$ & $\begin{array}{l}\text { Trypom. } \\
\text { forms }\end{array}$ & $\begin{array}{l}\text { Epim. } \\
\text { forms }\end{array}$ & $\begin{array}{l}\text { Amast. } \\
\text { forms }\end{array}$ & $\begin{array}{l}\text { Trypom. } \\
\text { forms }\end{array}$ & \\
\hline 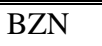 & $1015.8 \pm 1.1$ & $23.7 \pm 4.6$ & 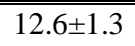 & $1818.7 \pm 1.1$ & $21.7 \pm 4.6$ & $12.8 \pm 0.7$ & $1015.8 \pm 1.1$ & $23.3 \pm 4.6$ & $6.2 \pm 0.7$ & $13.6 \pm 0.9$ \\
\hline 1 & $21.9 \pm 1.3$ & $19.3 \pm 1.4$ & $32.3 \pm 1.5$ & $48.2 \pm 4.0$ & $8.1 \pm 0.7$ & $6.6 \pm 0.3$ & $40.6 \pm 3.6$ & $21.4 \pm 1.7$ & $43.2 \pm 3.5$ & $236.9 \pm 12.6$ \\
\hline 2 & $30.6 \pm 2.0$ & $25.3 \pm 1.8$ & $31.4 \pm 1.3$ & $42.3 \pm 3.6$ & $10.1 \pm 0.3$ & $12.8 \pm 0.9$ & $23.6 \pm 1.4$ & $26.3 \pm 1.9$ & $43.2 \pm 4.0$ & $157.2 \pm 6.8$ \\
\hline 3 & $77.7 \pm 3.1$ & $11.7 \pm 1.8$ & $35.9 \pm 2.5$ & $35.5 \pm 2.8$ & $19.8 \pm 1.3$ & $0.5 \pm 0.1$ & $41.4 \pm 3.5$ & $20.7 \pm 0.9$ & $18.6 \pm 2.1$ & $1710.4 \pm 69.8$ \\
\hline 4 & $51.7 \pm 6.8$ & $27.9 \pm 4.7$ & $13.9 \pm 0.6$ & $14.0 \pm 0.9$ & $25.8 \pm 2.1$ & $45.8 \pm 3.5$ & $10.1 \pm 0.6$ & $8.7 \pm 0.7$ & $6.6 \pm 1.1$ & $896.0 \pm 45.7$ \\
\hline 5 & $28.5 \pm 0.8$ & $13.2 \pm 2.5$ & $9.6 \pm 0.4$ & $9.6 \pm 0.4$ & $14.8 \pm 0.8$ & $21.8 \pm 1.5$ & $30.1 \pm 1.3$ & $17.6 \pm 1.5$ & $19.6 \pm 1.3$ & $245.7 \pm 12.5$ \\
\hline 6 & $36.6 \pm 2.5$ & $19.8 \pm 1.9$ & $43.3 \pm 2.5$ & $48.1 \pm 3.7$ & $8.8 \pm 0.8$ & $52.4 \pm 2.3$ & $39.4 \pm 1.2$ & $16.3 \pm 1.2$ & $4.1 \pm 0.3$ & $553.7 \pm 14.3$ \\
\hline 7 & $30.7 \pm 1.1$ & $12.7 \pm 2.1$ & $0.3 \pm 0.2$ & $0.4 \pm 0.0$ & $4.9 \pm 1.0$ & $1.9 \pm 0.5$ & $12.3 \pm 1.0$ & $7.9 \pm 0.6$ & $5.1 \pm 0.3$ & $758.6 \pm 59.7$ \\
\hline 8 & $29.7 \pm 2.3$ & $31.7 \pm 2.6$ & $43.3 \pm 2.5$ & $30.1 \pm 1.3$ & $21.7 \pm 1.6$ & $32.3 \pm 2.9$ & $42.5 \pm 3.3$ & $18.7 \pm 1.4$ & $20.8 \pm 1.3$ & $129.8 \pm 8.8$ \\
\hline 9 & $86.7 \pm 4.6$ & $22.6 \pm 1.3$ & $39.5 \pm 3.1$ & $28.9 \pm 1.3$ & $20 . \pm 1.2$ & $27.3 \pm 1.2$ & $53.9 \pm 3.6$ & $32.0 \pm 2.0$ & $86.3 \pm 5.1$ & $70.8 \pm 4.6$ \\
\hline 10 & $26.0 \pm 0.8$ & $10.8 \pm 0.9$ & $20.3 \pm 1.8$ & $50.3 \pm 3.7$ & $22.8 \pm 1.3$ & $2,5 \pm 0.6$ & $179.2 \pm 6.7$ & $72.9 \pm 2.3$ & $33 \pm 2.5$ & $2846.3 \pm 123.8$ \\
\hline 11 & $28.0 \pm 1.7$ & $18.6 \pm 1.7$ & $26.8 \pm 1.9$ & $28.0 \pm 1.7$ & $20.2 \pm 0.9$ & $22.3 \pm 1.4$ & $12.8 \pm 0.6$ & $5.7 \pm 0.3$ & $4.6 \pm 0.2$ & $4.8 \pm 0.9$ \\
\hline 12 & $14.1 \pm 0.8$ & $10.0 \pm 0.4$ & $46.9 \pm 3.6$ & $28.0 \pm 2.0$ & $7.7 \pm 0.3$ & $22.3 \pm 0.7$ & $24.1 \pm 1.6$ & $16.3 \pm 0.6$ & $21.8 \pm 1.5$ & $65.8 \pm 1.8$ \\
\hline 13 & $2.5 \pm 0.3$ & $0.8 \pm 0.1$ & $0.7 \pm 0.01$ & $4.7 \pm 0.3$ & $2.0 \pm 1.0$ & $2.3 \pm 1.0$ & $21.2 \pm 1.1$ & $24.2 \pm 1.6$ & $37.5 \pm 2.2$ & $137.9 \pm 6.6$ \\
\hline 14 & $1.23 \pm 0.2$ & $2.6 \pm 1.4$ & $8.3 \pm 2.1$ & $4.2 \pm 0.1$ & $20.5 \pm 1.2$ & $6.6 \pm 1.2$ & $15.3 \pm 1.3$ & $8.3 \pm 0.4$ & $36.5 \pm 2.2$ & $30.1 \pm 2.6$ \\
\hline 15 & $3.4 \pm 0.7$ & $5.4 \pm 1.3$ & $3.9 \pm 0.6$ & $6.9 \pm 0.5$ & $8.6 \pm 0.7$ & $6.9 \pm 1.7$ & $27.7 \pm 1.6$ & $20.3 \pm 1.8$ & $26.4 \pm 1.2$ & $74.3 \pm 5.3$ \\
\hline 16 & $49.0 \pm 4.1$ & $23.9 \pm 1.6$ & $24.6 \pm 1.3$ & $27.6 \pm 1.6$ & $20.3 \pm 1.7$ & $25.5 \pm 0.9$ & $24.1 \pm 0.6$ & $12.4 \pm 0.8$ & $10.7 \pm 1.1$ & $102.8 \pm 4.7$ \\
\hline 17 & $50.6 \pm 2.8$ & $27.9 \pm 2.6$ & $21.8 \pm 1.5$ & $21.8 \pm 1.3$ & $17.6 \pm 1.6$ & $23.7 \pm 3.2$ & $17.8 \pm 0.8$ & $13.0 \pm 1.1$ & $14.2 \pm 0.8$ & $48.7 \pm 3.5$ \\
\hline 18 & $2.5 \pm 1.0$ & $1.7 \pm 0.4$ & $46.3 \pm 4.3$ & $69.1 \pm 4.9$ & $11.2 \pm 0.7$ & $29.3 \pm 1.8$ & $12.6 \pm 0.7$ & $6.2 \pm 0.7$ & $16.8 \pm 1.3$ & $0.3 \pm 0.0$ \\
\hline 19 & $1.4 \pm 0.5$ & $1.2 \pm 0.2$ & $0.58 \pm 0.1$ & $15.6 \pm 2.0$ & $11.6 \pm 0.7$ & $0.08 \pm 0.0$ & $18.8 \pm 1.4$ & $11.4 \pm 0.8$ & $50.9 \pm 2.3$ & $275.8 \pm 17.2$ \\
\hline 20 & $97.0 \pm 6.3$ & $22.4 \pm 1.2$ & $34.6 \pm 2.6$ & $199.5 \pm 13.1$ & $22.3 \pm 1.4$ & $56.3 \pm 3.1$ & $17.6 \pm 1.2$ & $14.8 \pm 0.8$ & $63.4 \pm 4.2$ & $322.8 \pm 30.1$ \\
\hline
\end{tabular}

Results are averages of four separate determinations. ${ }^{\mathrm{a}} \mathrm{IC}_{50}$ : is the concentration required to give $50 \%$ inhibition, calculated by linear regression analysis from the Kc values at the concentrations employed (1 to $2000 \mu \mathrm{M}) .{ }^{\mathrm{b}}$ Against Vero cells after $72 \mathrm{~h}$ of culture 
Table 5. Selectivity index and in vitro toxicity for the 20 derivatives of arylaminoketone intra and extracellular of T .cruzi strains.

\begin{tabular}{|c|c|c|c|c|c|c|c|c|c|c|}
\hline \multirow{2}{*}{ Comp. } & \multicolumn{3}{|c|}{$\begin{array}{l}\text { Selective Index }{ }^{\mathrm{c}} \\
\text { T. cruzi Arequipa strain }\end{array}$} & \multicolumn{3}{|c|}{$\begin{array}{l}\text { Selective Index }^{c} \\
\text { T. cruzi Tulahuen strain }\end{array}$} & \multicolumn{3}{|c|}{$\begin{array}{l}\text { Selective Index }{ }^{\mathrm{C}} \\
\text { T. cruzi SN3 strain }\end{array}$} & \multirow{2}{*}{$\begin{array}{l}\text { Vero cells } \\
\text { toxicity } \\
\mathrm{IC}_{50}(\mu \mathrm{M})\end{array}$} \\
\hline & $\begin{array}{l}\text { Epim. } \\
\text { forms }\end{array}$ & $\begin{array}{l}\text { Amast. } \\
\text { forms }\end{array}$ & $\begin{array}{l}\text { Trypom. } \\
\text { forms }\end{array}$ & $\begin{array}{l}\text { Epim. } \\
\text { forms }\end{array}$ & $\begin{array}{l}\text { Amast. } \\
\text { forms }\end{array}$ & $\begin{array}{l}\text { Trypom. } \\
\text { forms }\end{array}$ & $\begin{array}{l}\text { Epim. } \\
\text { forms }\end{array}$ & $\begin{array}{l}\text { Amast. } \\
\text { forms }\end{array}$ & $\begin{array}{l}\text { Trypom. } \\
\text { forms }\end{array}$ & \\
\hline$\overline{\text { BZN }}$ & 0.9 & 0.6 & 0.9 & 0.8 & 0.6 & 1.1 & 1.2 & 0.6 & 0.5 & $13.6 \pm 0.9$ \\
\hline 1 & $11(12)$ & $12(20)$ & $7(8)$ & $5(6)$ & 29 (49) & 36 (33) & $6(5)$ & $11(18)$ & $6(11)$ & $236.9 \pm 12.6$ \\
\hline 2 & $5(6)$ & $6(10)$ & $5(6)$ & $4(5)$ & $16(26)$ & 12 (10) & $7(6)$ & $6(10)$ & $4(7)$ & $157.2 \pm 6.8$ \\
\hline 3 & $22(25)$ & $146(244)$ & 48 (53) & $48(60)$ & $86(144)$ & 3420 (3109) & $41(34)$ & 83 (138) & 92 (184) & $1710.4 \pm 69.8$ \\
\hline 4 & 17 (19) & $32(53)$ & $864(72)$ & $64(80)$ & $35(58)$ & 20 (19) & $89(74)$ & $103(172)$ & $136(271)$ & $896.0 \pm 45.7$ \\
\hline 5 & $9(10)$ & $19(31)$ & $26(28)$ & $26(32)$ & 17 (28) & $11(10)$ & $8(7)$ & $14(23)$ & 12 (25) & $245.7 \pm 12.5$ \\
\hline 6 & 15 (17) & 28 (35) & $13(14)$ & 11 (19) & 63 (105) & 11 (10) & $14(12)$ & 34 (57) & 135 (270) & $553.7 \pm 14.3$ \\
\hline 7 & $25(27)$ & 60 (99) & 2528 (2810) & $1896(3160)$ & 155 (258) & 399 (333) & $62(51)$ & 96 (160) & 149 (299) & $758.6 \pm 59.7$ \\
\hline 8 & $4(5)$ & $4(7)$ & $3(3)$ & $4(5)$ & $6(10)$ & $4(4)$ & $3(2)$ & $7(12)$ & $6(12)$ & $129.8 \pm 8.8$ \\
\hline 9 & $1(1)$ & $3(5)$ & $2(3)$ & $2(3)$ & $3(6)$ & $3(2)$ & $1(1)$ & $2(4)$ & $1(1.6)$ & $70.8 \pm 4.6$ \\
\hline 10 & 109 (122) & 263 (439) & $140(156)$ & $57(78)$ & 125 (208) & 1138 (1035) & $16(14)$ & 39 (65) & 87 (172) & $2846.3 \pm 123.8$ \\
\hline 11 & $0(0)$ & $0(0)$ & $0(0)$ & $0(0)$ & $0(0)$ & $0(0)$ & $0(0)$ & $1(1)$ & $1(2)$ & $4.8 \pm 0.9$ \\
\hline 12 & $5(5)$ & $7(11)$ & $1(2)$ & $2(3)$ & $8(14)$ & $3(3)$ & $3(2)$ & $4(7)$ & $3(6)$ & $65.8 \pm 1.8$ \\
\hline 13 & $55(61)$ & $172(287)$ & 197 (219) & 30 (37) & 69 (115) & $60(55)$ & $6(5)$ & $6(9)$ & $4(7)$ & $137.9 \pm 6.6$ \\
\hline 14 & $24(27)$ & 12 (19) & $4(4)$ & $7(8)$ & $1(2)$ & $5(4)$ & $2(2)$ & $4(6)$ & $1(2)$ & $30.1 \pm 2.6$ \\
\hline 15 & $22(24)$ & $14(23)$ & $19(21)$ & $11(13)$ & $9(14)$ & $11(10)$ & $3(2)$ & $4(6)$ & $3(6)$ & $74.3 \pm 5.3$ \\
\hline 16 & $2(2)$ & $4(7)$ & $4(5)$ & $4(5)$ & $5(8)$ & $4(4)$ & $4(4)$ & $8(14)$ & 10 (19) & $102.8 \pm 4.7$ \\
\hline 17 & $1(1)$ & $2(3)$ & $2(2)$ & $2(3)$ & $3(5)$ & $2(2)$ & $3(2)$ & $4(6)$ & $3(7)$ & $48.7 \pm 3.5$ \\
\hline 18 & $0(0)$ & $0(0)$ & $0(0)$ & $0(0)$ & $0(0)$ & $0(0)$ & $0(0)$ & $0(0)$ & $0(0)$ & $0.3 \pm 0.0$ \\
\hline 19 & 197 (219) & 230 (383) & $552(528)$ & $18(22)$ & $16(26)$ & 3447 (3134) & 15 (12) & $24(40)$ & $5(11)$ & $275.8 \pm 17.2$ \\
\hline 20 & $3(4)$ & $14(24)$ & $9(10)$ & $2(2)$ & $14(24)$ & $6(5)$ & 18 (15) & $22(36)$ & $5(10)$ & $322.8 \pm 30.1$ \\
\hline
\end{tabular}

${ }^{c}$ Selectivity index $=\mathrm{IC}_{50}$ Vero cells toxicity//C 50 activity on extracellular or intracellular forms of the parasite. In brackets: number of times the compound SI exceeded the reference drug SI. 
Table 6. Weight percent of spleens of different groups of mice.

\begin{tabular}{ll|ll}
\hline \hline Treatment (50 mg) & Weight percent & Treatment $(100 \mathrm{mg})$ & Weight percent \\
\hline \hline Control (untreated) & 1.603 & Control (untreated) & 1.603 \\
3 & 1.174 & BZN & 0.837 \\
4 & 1.621 & 3 & 0.729 \\
7 & 1.061 & 4 & 1.041 \\
10 & 1.171 & 7 & 0.825 \\
& & 10 & 0.892 \\
\hline
\end{tabular}


Table 7. Results of the Ames test of compound 4.

\begin{tabular}{|c|c|c|c|c|c|c|c|c|c|c|}
\hline \multirow{3}{*}{$\begin{array}{l}\text { Treatment } \\
\text { Preincubation assay }\end{array}$} & \multicolumn{10}{|c|}{ Mean number of revertant colonies per plate } \\
\hline & \multicolumn{2}{|l|}{ TA98 } & \multicolumn{2}{|l|}{ TA100 } & \multicolumn{2}{|l|}{ TA102 } & \multicolumn{2}{|c|}{ TA1535 } & \multicolumn{2}{|l|}{ TA1537 } \\
\hline & $-S 9$ & +S9 & -S9 & +S9 & -S9 & $+\mathrm{S} 9$ & -S9 & +S9 & -S9 & +S9 \\
\hline Negative control & $12 \pm 4$ & $12 \pm 0$ & $114 \pm 24$ & $119 \pm 6$ & $413 \pm 80$ & $420 \pm 130$ & $10 \pm 1$ & $8 \pm 3$ & $2 \pm 2$ & $4 \pm 1$ \\
\hline \multicolumn{11}{|l|}{ Test dose ( $\mu \mathrm{g} /$ plate) } \\
\hline 0.03 & $15 \pm 1$ & $12 \pm 1$ & $90 \pm 20$ & $128 \pm 8$ & $532 \pm 69$ & $550 \pm 65$ & $13 \pm 2$ & $11 \pm 2$ & $2 \pm 1$ & $2 \pm 1$ \\
\hline 0.08 & $16 \pm 3$ & $15 \pm 2$ & $100 \pm 3$ & $131 \pm 18$ & $484 \pm 61$ & $504 \pm 25$ & $13 \pm 3$ & $11 \pm 5$ & $3 \pm 2$ & $4 \pm 3$ \\
\hline 0.25 & $14 \pm 2$ & $10 \pm 5$ & $107 \pm 13$ & $120 \pm 16$ & $459 \pm 28$ & $553 \pm 85$ & $11 \pm 4$ & $16 \pm 2$ & $4 \pm 3$ & $4 \pm 2$ \\
\hline 0.75 & $16 \pm 1$ & $12 \pm 2$ & $109 \pm 13$ & $136 \pm 4$ & $473 \pm 42$ & $546 \pm 63$ & $13 \pm 4$ & $8 \pm 1$ & $2 \pm 1$ & $2 \pm 1$ \\
\hline 2.25 & $14 \pm 2$ & $11 \pm 3$ & $110 \pm 12$ & $139 \pm 4$ & $487 \pm 29$ & $540 \pm 76$ & $9 \pm 1$ & $12 \pm 3$ & $4 \pm 3$ & $2 \pm 2$ \\
\hline Positive control & $1608 \pm 352$ & $1250 \pm 85$ & $704 \pm 9$ & $1900 \pm 164$ & $739 \pm 36$ & $1142 \pm 148$ & $151 \pm 8$ & $239 \pm 69$ & $791 \pm 32$ & $243 \pm 18$ \\
\hline
\end{tabular}


Table 8. Results of the Ames test of compound 7.

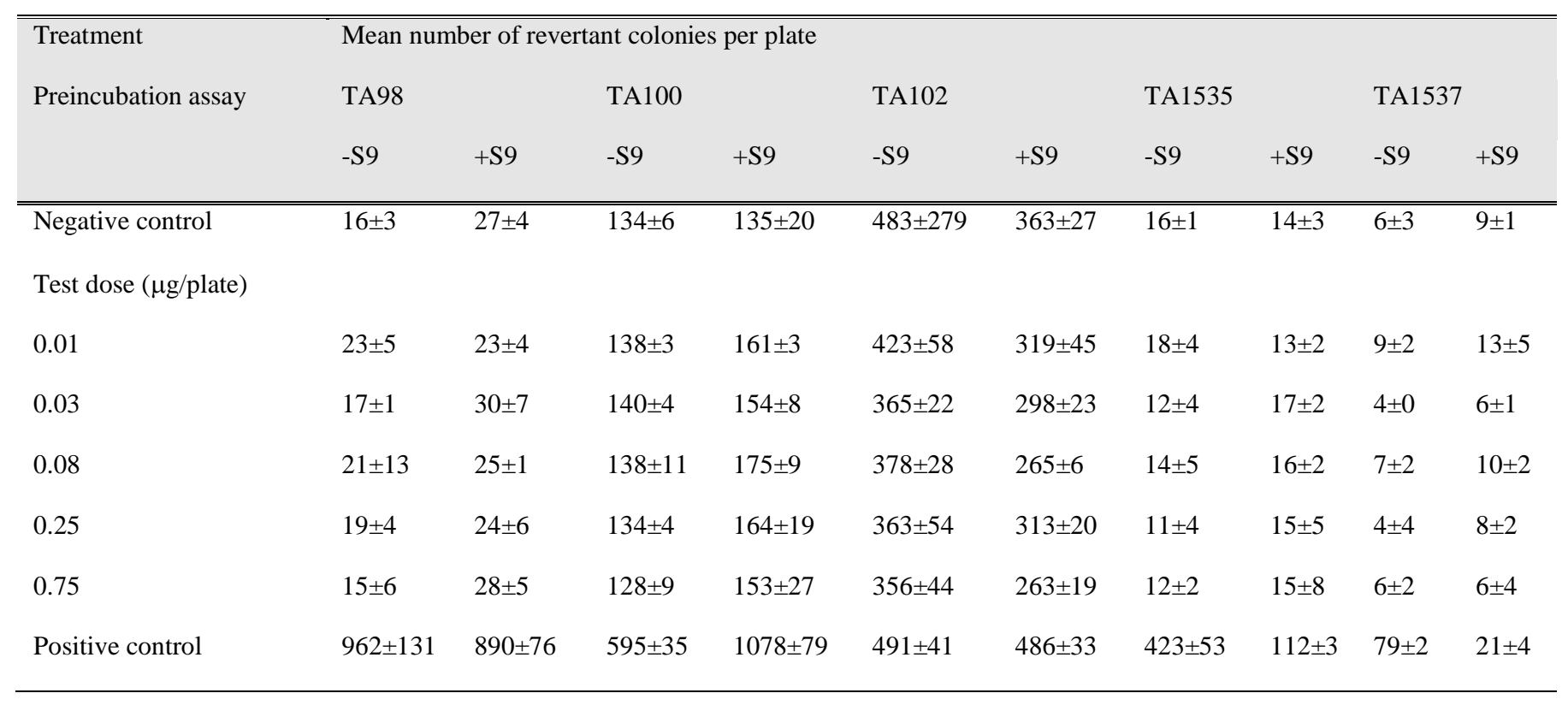


Figure 1. General method of synthesis of new arylaminoketone derivatives.

i: corresponding amine, 1,3-dioxolane, $\mathrm{H}^{+}$, reflux.

Figure 2. Reduction of the infection of Trypanosoma cruzi in Vero cells treated with (-口-) BZN,

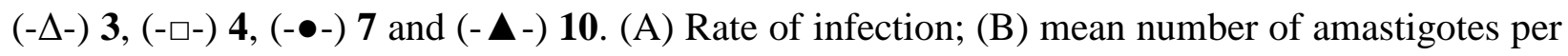
infected Vero cells; (C) number of trypomastigotes in the culture medium. Measured at $\mathrm{IC}_{25}$. Values are the means of the three separate experiments.

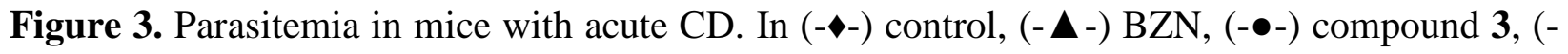
-) compound 4, (- $\Delta-)$ compound 7 and (-口-) compound 10. In all cases, compounds were orally administered using, for each compound, $100 \mathrm{mg} / \mathrm{kg}$ of body mass. Values constitute means of six mice \pm standard deviation. Treatment days are represented in grey.

Figure 4. Immunosuppression in vivo assay for mice untreated and treated with $100 \mathrm{mg} / \mathrm{kg}$ of body mass of BZN, 3, 4, 7 and 10. Figure shows the reactivation of blood parasitemia after the immunosuppression cycles by fresh blood containing to the peak day parasitemia during acute phase.

Figure 5. Shows differences in the IgG levels measured by ELISA at different day postinfection.

Figure 6. Polymerase chain reaction (PCR) analysis of the 8 target organs on day 120 after infection. Lanes: M, base pair marker; 1: PCR negative control; 2: PCR positive control; 3: PCR adipose tissue; 4: PCR brain tissue; 5: PCR heart tissue; 6: PCR esophagus tissue; 7: PCR stomach tissue; 8: PCR bone marrow tissue; 9: PCR muscle tissue; 10: PCR lung tissue. * This 
means that $1 / 6$ of the corresponding organ PCR products showed 300 bp band on electrophoresis.

Figure 7. A) Inhibition in vitro (\%) of Fe-SOD from epimastigotes of Trypanosoma cruzi for compounds (activity $25.4 \pm 3.1 \mathrm{U} / \mathrm{mg}$ ). B) Inhibition in vitro (\%) of CuZn-SOD from human erythrocytes for compounds (activity 23.36 $\pm 2.5 \mathrm{U} / \mathrm{mg}$ ). Activity differences in the control homogenate vs. the sample incubated using compounds were identified by the Newman-Keuls test. Values are the average of three separate rate determinations.

Figure 8. Percentages of variation among peaks of catabolites excreted by epimastigotes of Trypanosoma cruzi exposed to compounds 3, 4, $\mathbf{7}$ and $\mathbf{1 0}$ at their $\mathrm{IC}_{25}$ in comparison to a control incubated $96 \mathrm{~h}$.

Figure 9. Docking results for the binding of benzothiophenes derivatives 3 (up-left), 4 (downleft), $\mathbf{7}$ (up-right) and $\mathbf{1 0}$ (down-right) to the Trypanosoma cruzi Fe-SOD (a) and the human CuZn-SOD (b) enzymes. In the center, an image of the entire enzyme with the compounds binding at the top of the dimer interface is shown. Residues forming the inhibitor binding site are shown. Color scheme: oxygen (red), nitrogen (blue), sulfur (yellow), carbon (pale pink for compound $\mathbf{3}$, orange for compound $\mathbf{4}$, blue for compound $\mathbf{7}$ and magenta for compound $\mathbf{1 0}$. For the proteins, one monomer is shown in green and the other in yellow). The ions are shown as spheres. Figures were created with The PyMOL Molecular Graphics System, Version 1.8 Schrödinger, LLC. 
$\mathrm{Ar}_{1} \stackrel{\mathrm{O}}{\mathrm{CH}_{3}} \stackrel{\mathrm{i}}{\longrightarrow} \mathrm{Ar}_{1}^{\mathrm{O}} \overbrace{\text { amine }}-\mathrm{Ar}_{2}$

Figure 1. General method of synthesis of new arylaminoketone derivatives.

i: corresponding amine, 1,3-dioxolane, $\mathrm{H}^{+}$, reflux. 


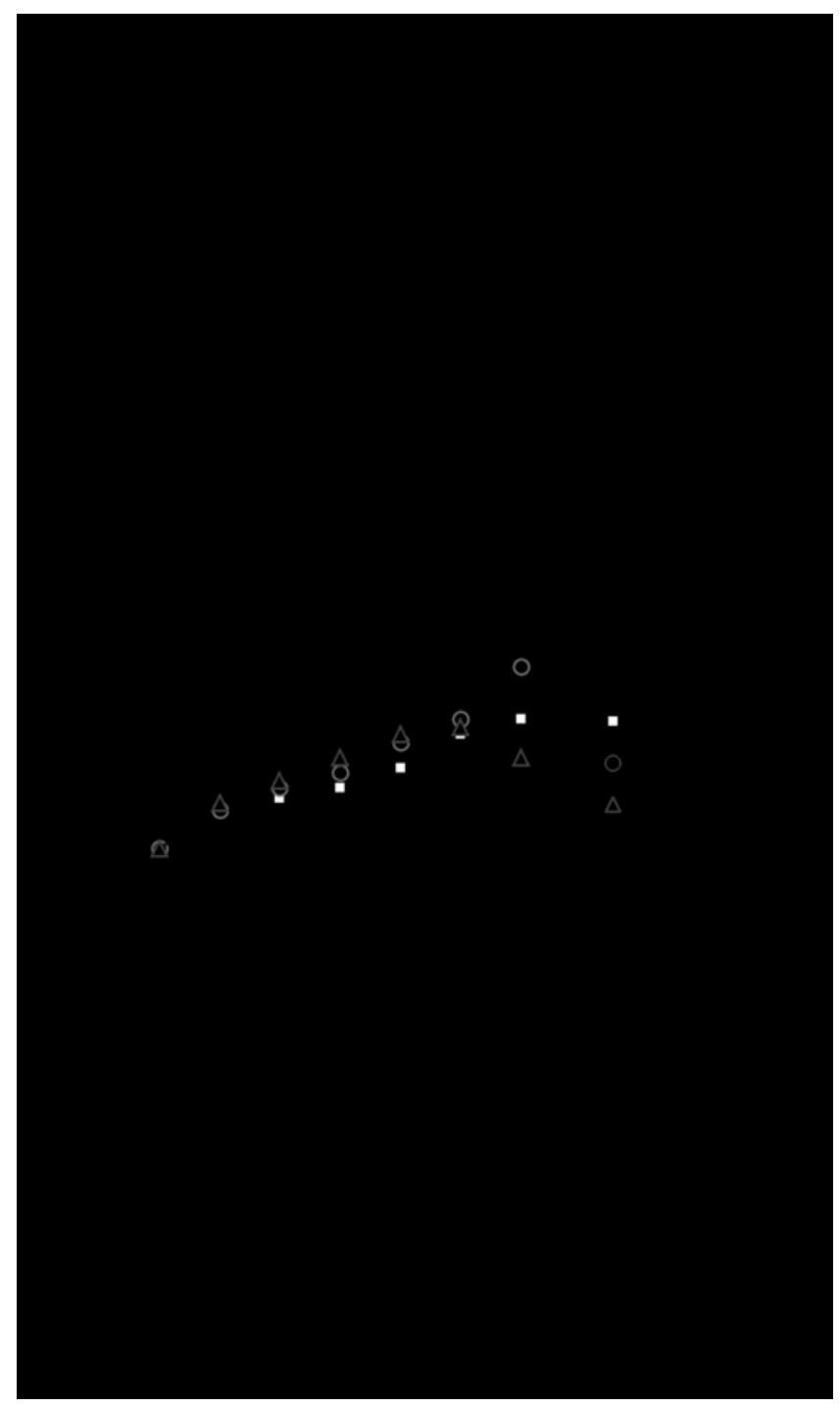

Figure 2. Reduction of the infection of Trypanosoma cruzi in Vero cells treated with (-口-) BZN,

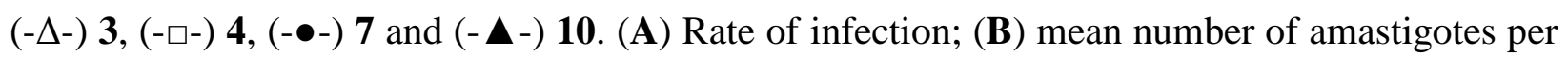
infected Vero cells; (C) number of trypomastigotes in the culture medium. Measured at $\mathrm{IC}_{25}$. Values are the means of the three separate experiments. 


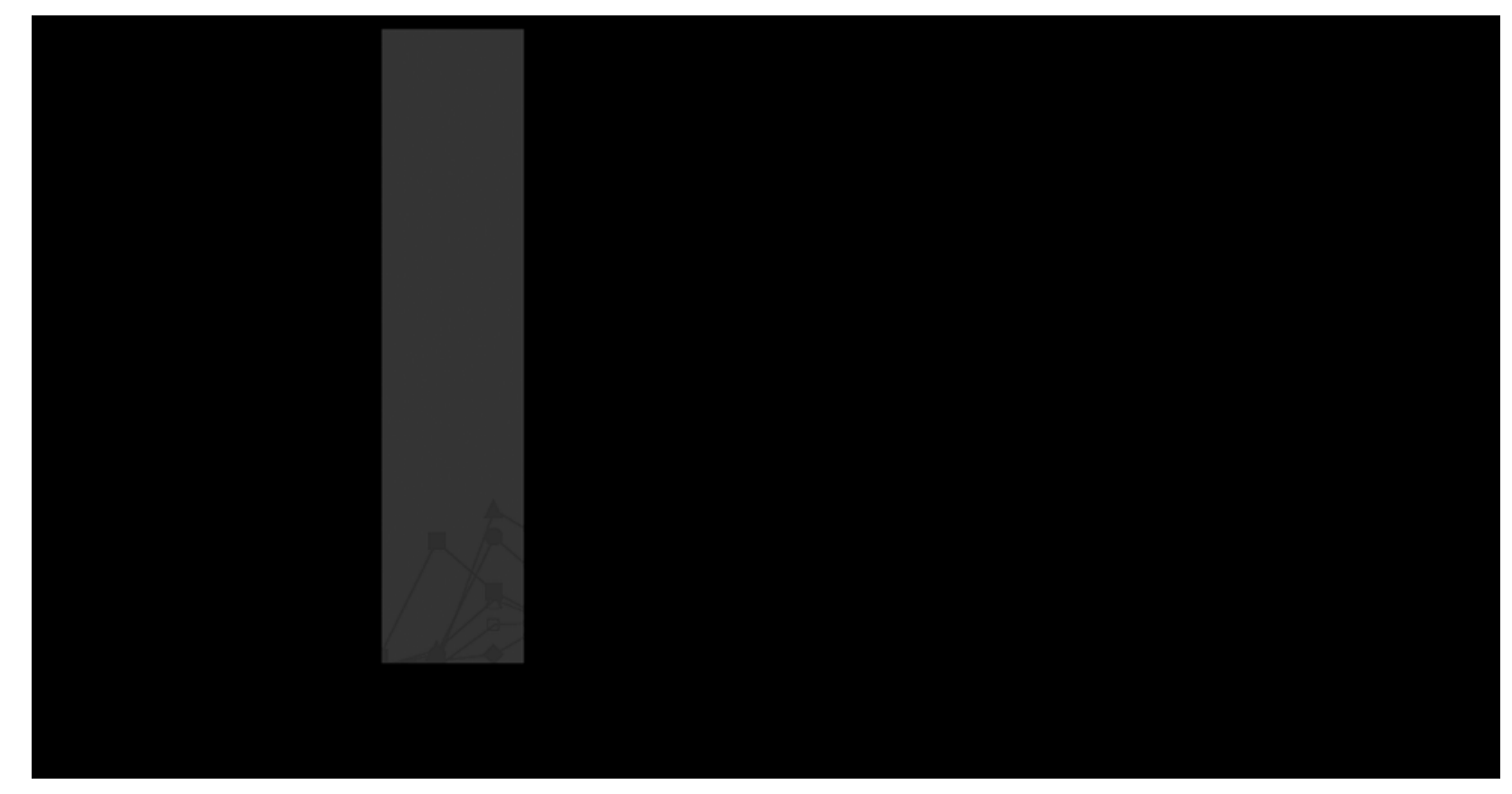

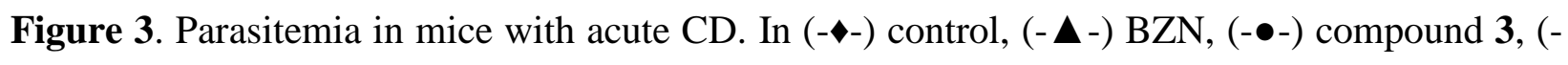
-) compound 4, (- $\left.\Delta^{-}\right)$compound 7 and (-口-) compound 10. In all cases, compounds were orally administered using, for each compound, $100 \mathrm{mg} / \mathrm{kg}$ of body mass. Values constitute means of six mice \pm standard deviation. Treatment days are represented in grey. 


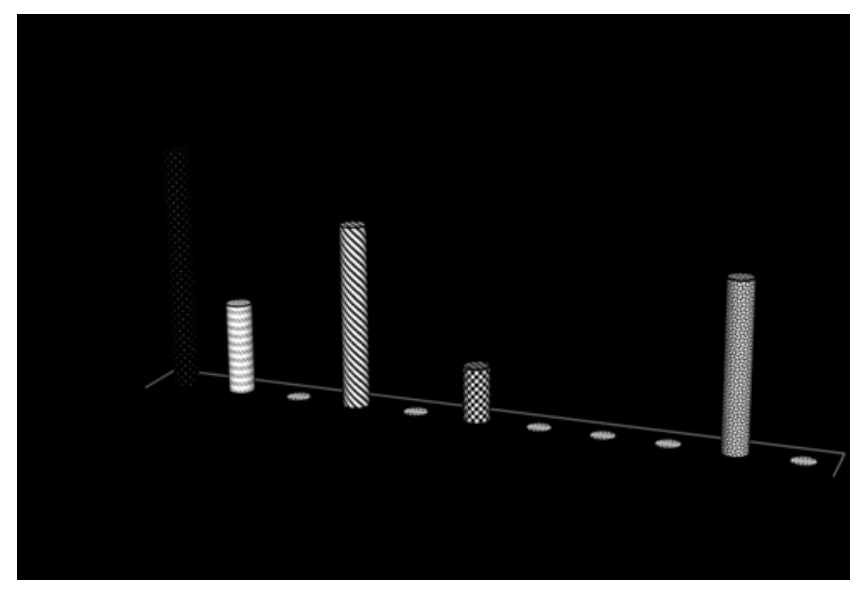

Figure 4. Immunosuppression in vivo assay for mice untreated and treated with $100 \mathrm{mg} / \mathrm{kg}$ of body mass of BZN, 3, 4, 7 and 10. Figure shows the reactivation of blood parasitemia after the immunosuppression cycles by fresh blood containing to the peak day parasitemia during acute phase. 


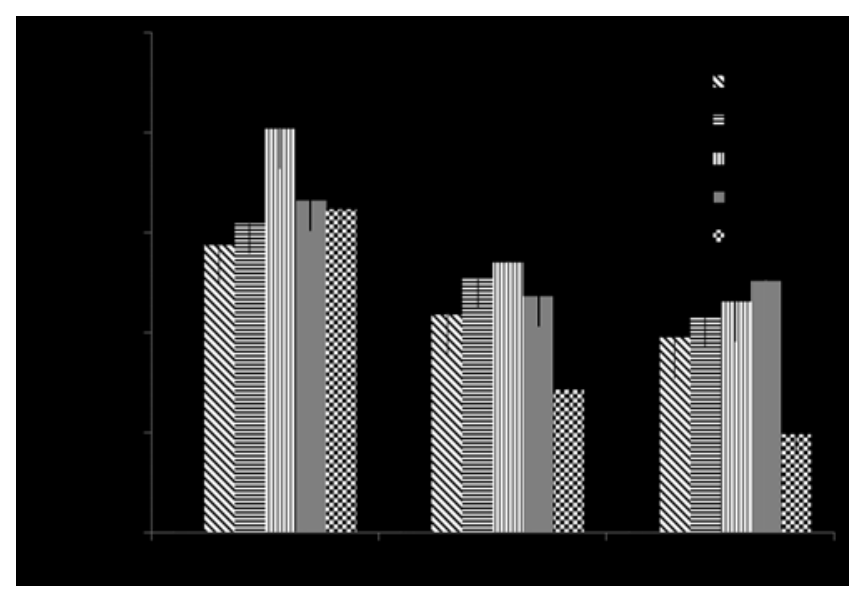

Figure 5. Shows differences in the IgG levels measured by ELISA at different day postinfection. 


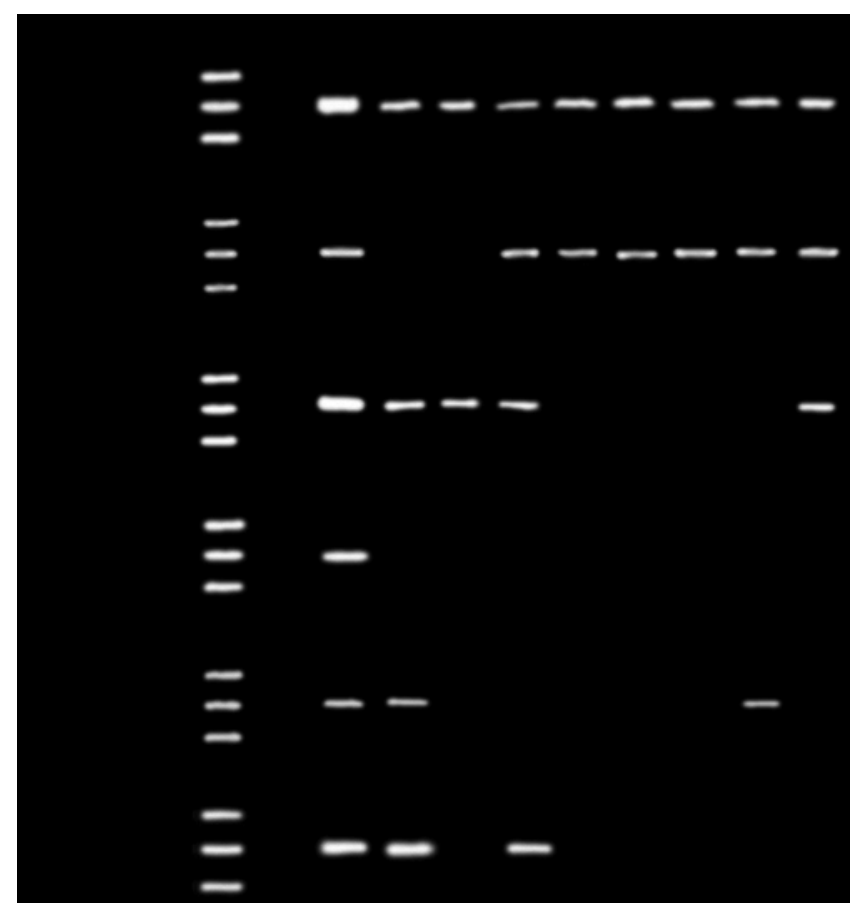

Figure 6. Polymerase chain reaction (PCR) analysis of the 8 target organs on day 120 after infection. Lanes: M, base pair marker; 1: PCR negative control; 2: PCR positive control; 3: PCR adipose tissue; 4: PCR brain tissue; 5: PCR heart tissue; 6: PCR esophagus tissue; 7: PCR stomach tissue; 8: PCR bone marrow tissue; 9: PCR muscle tissue; 10: PCR lung tissue. * This means that $1 / 6$ of the corresponding organ PCR products showed 300 bp band on electrophoresis. 


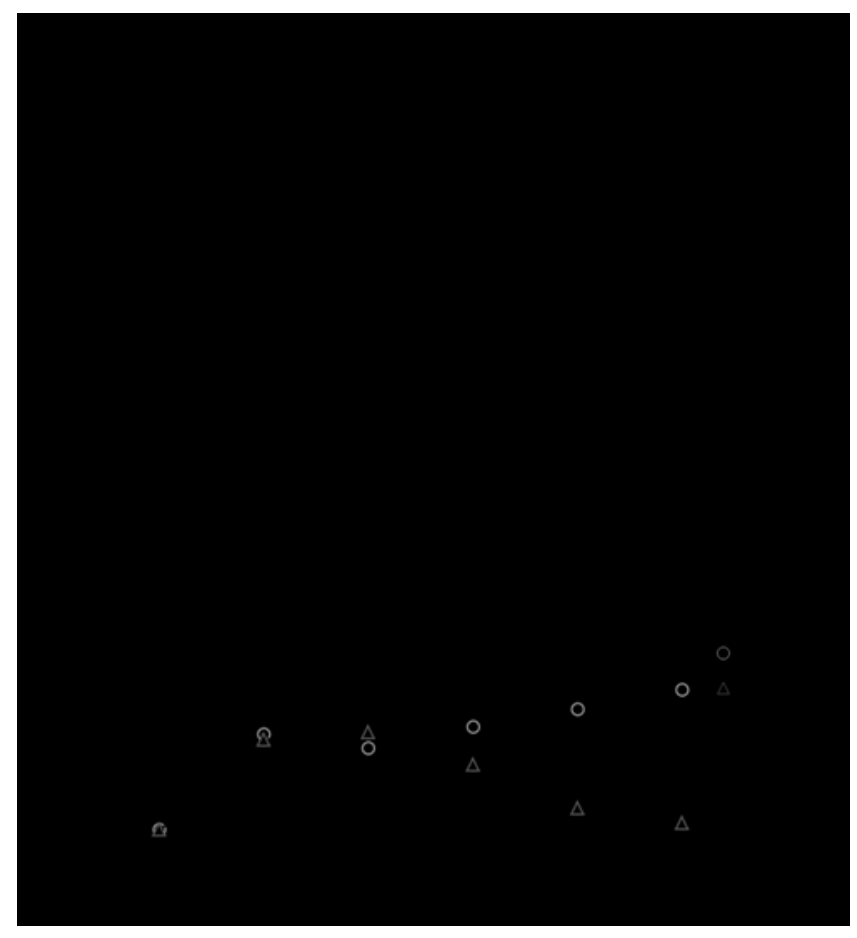

Figure 7. A) Inhibition in vitro (\%) of Fe-SOD from epimastigotes of Trypanosoma cruzi for compounds (activity $25.4 \pm 3.1 \mathrm{U} / \mathrm{mg}$ ). B) Inhibition in vitro (\%) of CuZn-SOD from human erythrocytes for compounds (activity 23.36 $2.5 \mathrm{U} / \mathrm{mg}$ ). Activity differences in the control homogenate vs. the sample incubated using compounds were identified by the Newman-Keuls test. Values are the average of three separate rate determinations. 


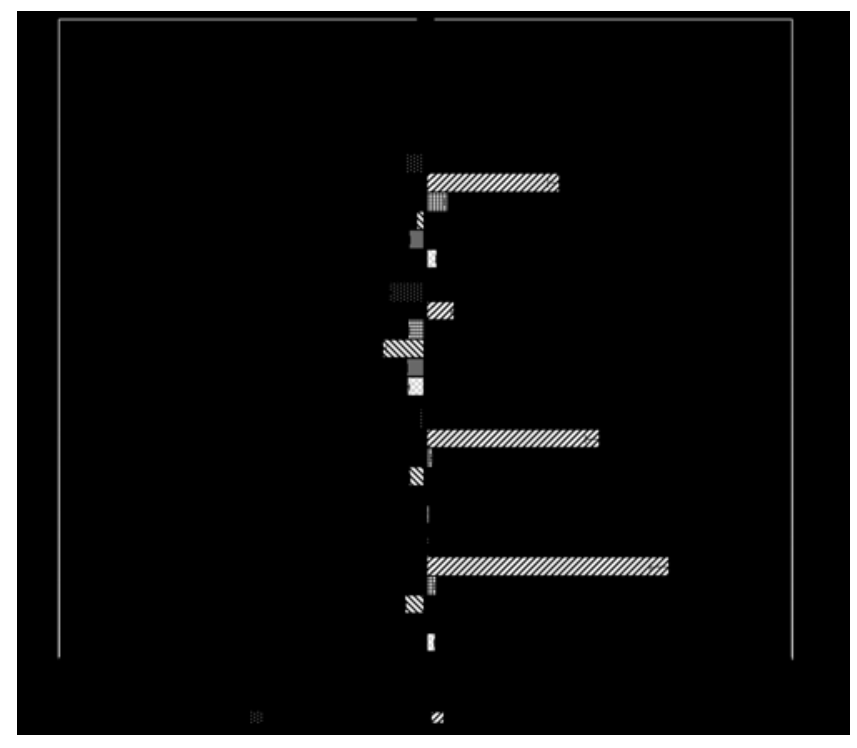

Figure 8. Percentages of variation among peaks of catabolites excreted by epimastigotes of Trypanosoma cruzi exposed to compounds 3, 4, 7 and $\mathbf{1 0}$ at their $\mathrm{IC}_{25}$ in comparison to a control incubated 96 h. 
a)

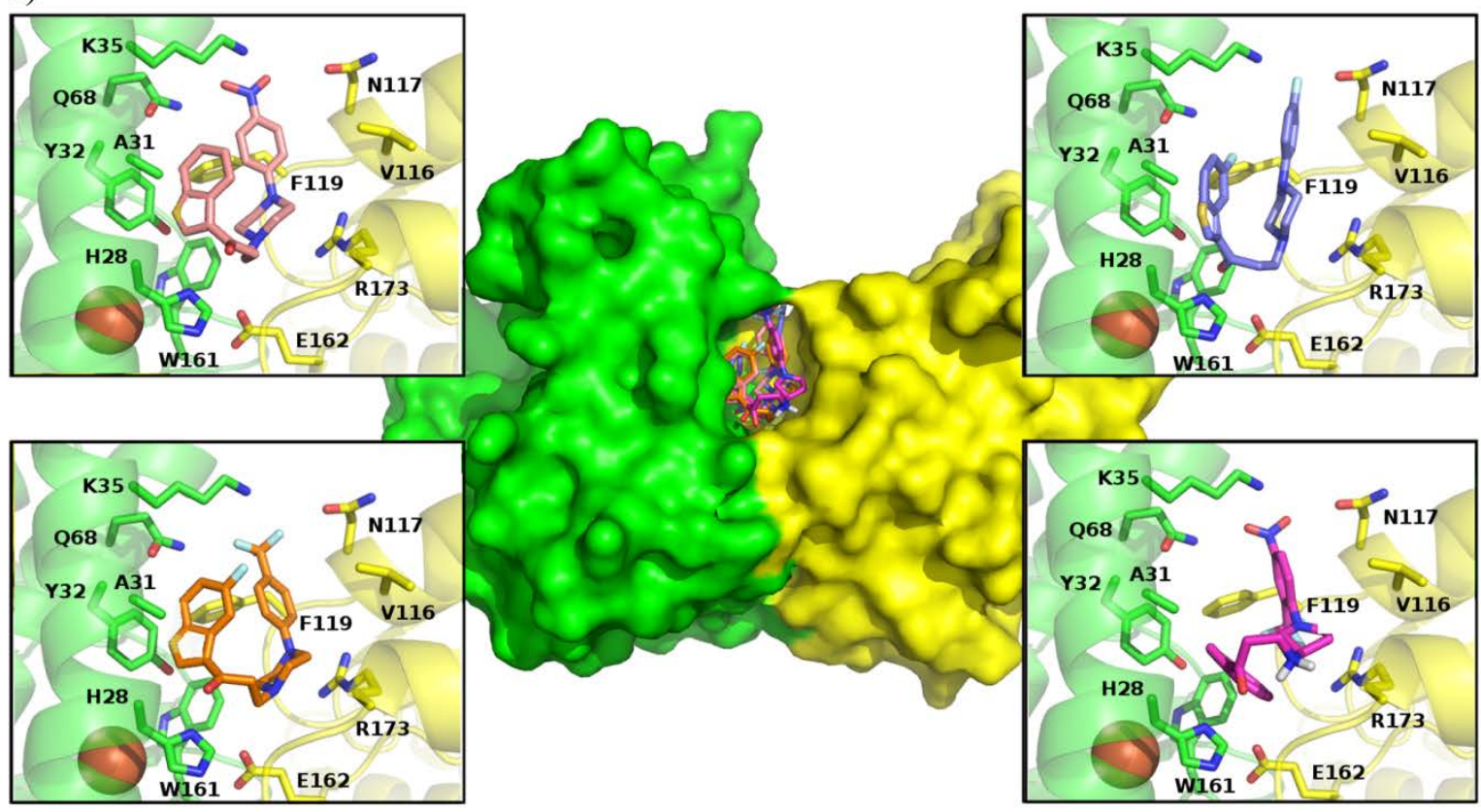

b)
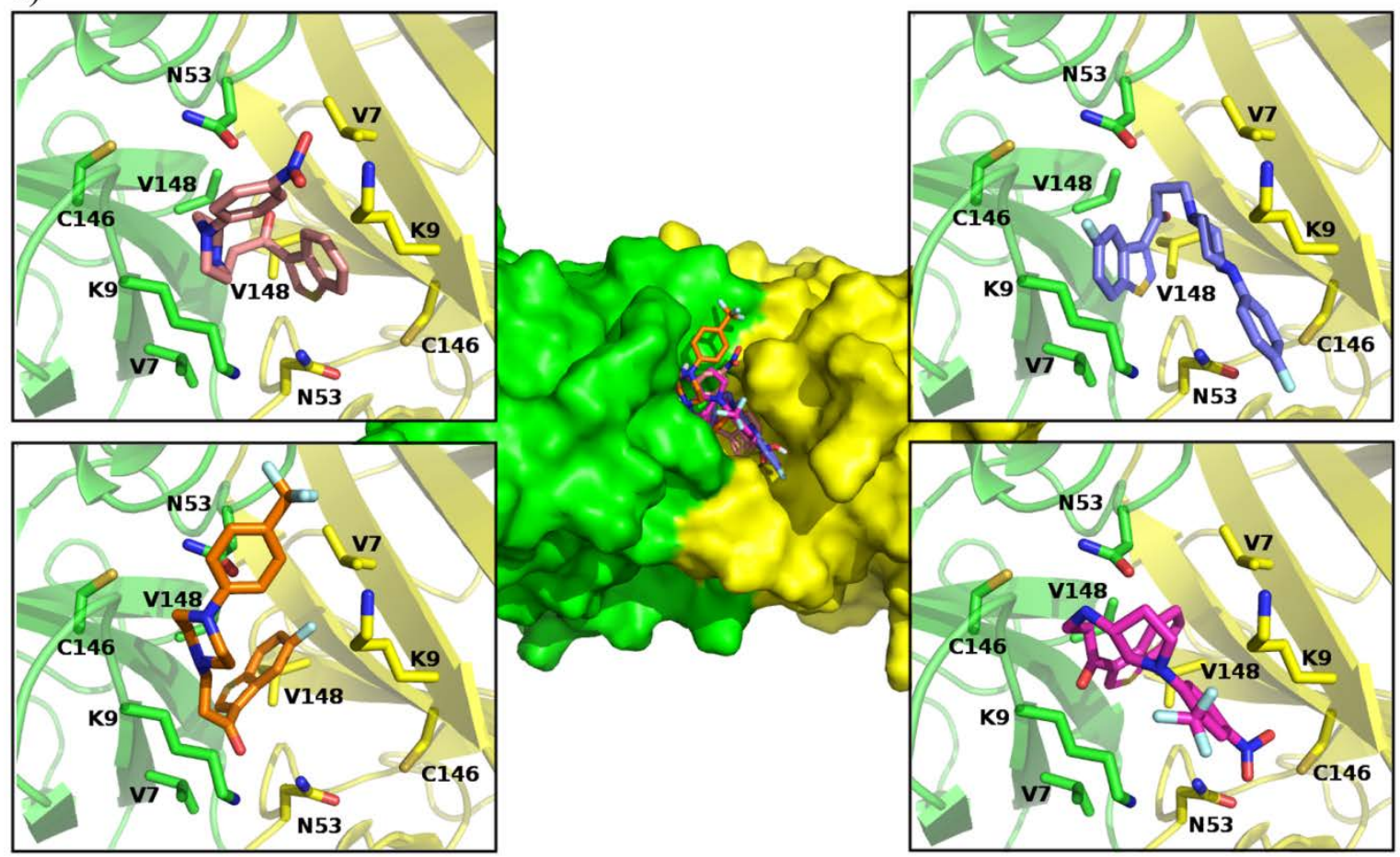
Figure 9. Docking results for the binding of benzothiophenes derivatives 3 (up-left), 4 (downleft), 7 (up-right) and 10 (down-right) to the Trypanosoma cruzi Fe-SOD (a) and the human CuZn-SOD (b) enzymes. In the center, an image of the entire enzyme with the compounds binding at the top of the dimer interface is shown. Residues forming the inhibitor binding site are shown. Color scheme: oxygen (red), nitrogen (blue), sulfur (yellow), carbon (pale pink for compound 3, orange for compound $\mathbf{4}$, blue for compound $\mathbf{7}$ and magenta for compound $\mathbf{1 0}$. For the proteins, one monomer is shown in green and the other in yellow). The ions are shown as spheres. Figures were created with The PyMOL Molecular Graphics System, Version 1.8 Schrödinger, LLC. 
Insert Table of Contents Graphic and Synopsis Here

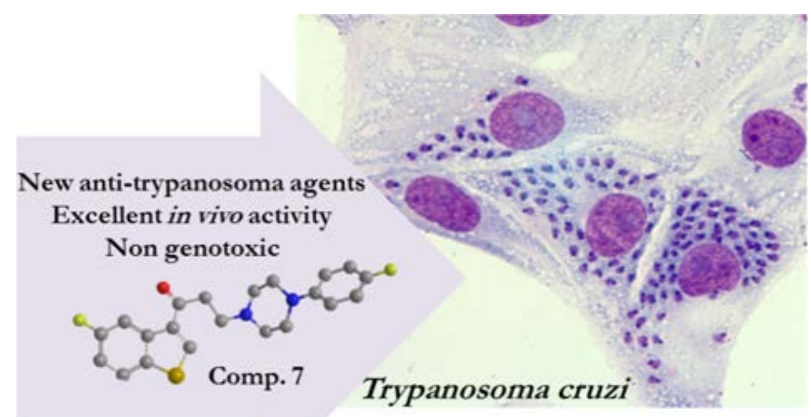

